\title{
Evaluation of Energy Consumption of Proactive, Reactive, and Hybrid Routing Protocols in Wireless Mesh Networks Using 802.11 Standards
}

\author{
Sidoine D. Samo, Jean Louis E. K. Fendji \\ Department of Computer Engineering, Institute of Technology, University of Ngaoundéré, Ngaoundéré, Cameroon \\ Email: samosidoine@gmail.com, jlfendji@univ-ndere.cm
}

How to cite this paper: Samo, S.D. and Fendji, J.L.E.K. (2018) Evaluation of Energy Consumption of Proactive, Reactive, and Hybrid Routing Protocols in Wireless Mesh Networks Using 802.11 Standards. Journal of Computer and Communications, 6, 1-30. https://doi.org/10.4236/jcc.2018.64001

Received: March 4, 2018

Accepted: April 16, 2018

Published: April 19, 2018

Copyright ( $\odot 2018$ by authors and Scientific Research Publishing Inc. This work is licensed under the Creative Commons Attribution International License (CC BY 4.0).

http://creativecommons.org/licenses/by/4.0/ (c) (i) Open Access

\begin{abstract}
This paper provides a deep evaluation of the energy consumption of routing protocols. The evaluation is done along with other metrics such as throughput and packet delivery ratio (PDR). We introduce two more metrics to capture the efficiency of the energy consumption: e-throughput and e-PDR. Both are ratios in relation to the energy. We consider the three low layers of the stack. Three types of routing protocols are used: proactive, reactive, and hybrid. At the MAC and PHY layer, three radio types are considered: $802.11 \mathrm{a} / \mathrm{b} / \mathrm{g}$. Finally, the number of nodes is varying in random topologies, with nodes being static or mobile. Simulations are conducted using NS3. The parameters of a real network interface card are used. From the results in mobile position scenarios, no protocol is outperforming the others; even if OLSR has the lowest energy consumption, most of the time. However, in constant position scenarios, AODV consumed a lower energy, apart from the scenarios using the 802.11a standard where HWMP energy consumption is the lowest. Regarding the energy efficiency, AODV protocols provided the best e-throughput and OLSR the best e-PDR in overall configurations. A framework for selecting energy-efficient routing protocol depending on network characteristics is proposed at the end.
\end{abstract}

\section{Keywords}

Energy consumption, Routing Protocols, Wireless Mesh Networks, e-Throughput, e-PDR

\section{Introduction}

Wireless networks are attracting a lot of interest from researchers since more 
than two decades. This easy-to-deploy technology appears as an appealing solution to reduce the digital divide and to connect hard-to-wire areas. Wireless networks are more and more adopted in our environment from infrastructureless to well-organized architecture. An ad-hoc network is composed of a set of nodes coming together in order to create a network without a central infrastructure. This type of network is self-organized; it can reconfigure itself when a node joins or leaves the network. Nodes can be fixed or mobile. In the latter case, we talk about mobile ad-hoc networks usually shortened MANETs [1]. Communication is pairwise in a MANET. A node can communicate with another one through a set of intermediate nodes, which may act as routers. Avoiding communication from passing through a central node provides some robustness to the network. When a node fails, other nodes can still communicate. MANETs can be considered as a special type of wireless mesh networks (WMNs): client mesh network [2].

The performance of a MANET or a WMN depends on one hand on the routing decisions made at the network layer by underlying routing protocols. On the other hand, the performance depends on the underlying MAC and PHY layers and on the topology (fixed or dynamic) of the network.

IETF's MANET working group has proposed several classical routing protocols and performance factors, but without considering the related energy factor [3]. Despite the lot of work devoted to the performance improvement of routing protocols, the energy consumption remains a critical issue in these networks, especially when most of the nodes are powered by a limited source. As a result, the energy consumption in MANETs is a research field, which is still attracting a lot of attention from researchers. This issue is also becoming more and more relevant in WMNs. Mesh routers, which constitute the backbone, have been considered as fixed during earlier planning of WMNs. But in more recent scenarios, mesh routers started to be equipped with batteries like in robots [4] or a solar panel or a generator, as it is the case in remote or rural areas [5] [6] [7]. This shows the importance of studying the energy consumption not only on MANETs but also in WMNs in order to improve the lifetime of the network. Which routing protocol is more energy-efficient in a particular network configuration? The configuration may depend on the size of the network in terms of the number of nodes, the mobility of nodes and the 802.11 standard.

Although several works focused on the definition of energy-aware routing protocols in wireless networks, few works have tackled the evaluation of energy consumption of the existing routing protocols [8] [9]. The aim of this work is to provide a framework for choosing a suitable routing protocol according to the 802.11 radio type and the size of the network in terms of the number of nodes.

This work provides a deeper evaluation of the energy consumption in wireless networks. Three types of routing protocols are considered: proactive, reactive and hybrid. Since the energy-efficiency of a routing protocol may affect other performance metrics, the energy consumption is evaluated in relation with other 
network properties. We introduce two metrics: e-throughput, which is the ratio between the consumed energy and throughput, and the e-PDR, which is the ratio between the consumed energy and the PDR.

The rest of the paper is organized as follows: Section 2 presents the different types of routing protocols in wireless mesh and ad-hoc networks. Section 3 summarizes previous works on energy consumption evaluation in routing protocols. The simulation setup is presented in section 4; followed by the results and discussions in section 5 .

\section{Routing Protocols in Ad-Hoc and Mesh Networks}

Routing protocols are operating at the network and at the MAC layer. They define how packet routes are discovered and how packets are sent in the network. Three routing protocols have been selected for the comparison: AODV (Ad hoc On-Demand Distance Vector) as a reactive protocol, OLSR (Optimized Link State Routing protocol) as a proactive protocol, and HWMP (Hybrid Wireless Mesh Protocol) as a hybrid protocol. They have been selected among the lengthy list of routing protocols because of their popularity and their mature implementation in Network Simulator. Moreover, AODV, and OLSR have already been defined in RFCs.

\subsection{AODV}

Reactive routing protocols are waiting for the demand before finding the route to the destination of a packet. AODV remains the most used among all reactive routing protocols. Several reactive routing protocols are based on this protocol. The AODV protocol is defined in RFC 3561 [10]. Since nodes are mobile, the topology is consequently subject to change; AODV allows nodes to obtain routes rapidly for new destinations. It is based on other distance vector protocols such as DSDV and DSR.

The discovery process used to determine unicast route to the destination precedes data transmission. A route request packet RREQ is flooded from the sending node during this process. Each node, which receives this packet, forwards it to other nodes until the destination is found. All intermediates nodes consider the route to the source contained in the RREQ packet during this first step. Once the destination is reached, this node sends a route reply RREP packet. This packet follows the reverse path taken by the RREQ. On the way back to the source, RREP provides a route to the destination to all intermediate nodes. The discovery process ends when RREP reaches the source. The transmission of packets can really start. At this point, each intermediate node knows the neighbor to which it should forward packets in order to reach the source or the destination. By this way, it is no longer necessary to keep the addresses of all intermediate nodes between the source and the destination. The routing overhead is therefore considerably reduced. The operation of AODV is loop-free due to the use of destination sequence numbers as described in [10]. 


\subsection{OLSR}

Proactive routing protocols do not wait for a demand before finding the route to a destination; they maintain a table used for this purpose. This is why they are also called table-driving routing protocols. The Optimized Link State Routing (OLSR) protocol, in its first version, has been defined in RFC 3626 [11] in 2003. A second version has been proposed in RFC 7181 in 2014 . The route is build beforehand for data transmission by maintaining a routing table at each node. OLSR makes therefore use of the following mechanisms as described in [11]:

- Link Sensing: it aims to check the connectivity between nodes. It is accomplished through periodic emission of HELLO messages over the interfaces through which connectivity is checked. A separate HELLO message is generated for each interface.

- Neighbor detection: it depends on the number of interfaces per node. The neighbor set of a node may be deducted from the information exchanged as part of link sensing in a network with single interface nodes. The address of a node is that one of its single interface.

- MPR Selection and MPR Signaling: each node selects a set of its neighbor nodes as special nodes called multipoint relays (MPRs). Only those MPRs will retransmit broadcast messages, in such a way that this message will be received by all nodes two hops away.

- Topology Control Message Diffusion: The routing table at each node is constructed using topology control by means of Topology Control (TC) packets, which are forwarded only by MPR.

- Route Calculation: The routing table at each node, containing sufficient link-state information, will be used for route calculation.

\subsection{HWMP}

The Hybrid Wireless Mesh Protocol (HWMP) is a routing protocol defined in IEEE 802.11s and dedicated to Wireless Mesh Networks [12]. It combines the flexibility of on-demand routing with proactive topology tree extensions. HWMP supports two modes of operation depending on the configuration: reactive mode and proactive mode. The latter makes use of additional primitives to proactively set up a distance-vector tree rooted at a single root mesh point (MP). The two modes of HWMP are not exclusive and may be used concurrently. They make use of four types of control messages: Route Request (RREQ), Route Reply (RREP), Root Announcement (RANN), and Route Error (RERR). The first three types of control messages contain a metric field in order to propagate the metric information between MPs.

We consider the reactive mode in this paper, since HWMP is basically a reactive protocol. HWMP has just been augmented by a proactive mechanism designed to permit that a node announces itself as the root of a tree based topology. In reactive mode, when a source MP needs to find a route, it broadcasts a RREQ specifying a destination MP and the metric field is initialized to 0 . When 
a MP receives a RREQ it creates a route to the source or updates its current one. The RREQ is forwarded if a new route is created or an existing one is modified. Each MP may receive multiple copies of the same RREQ coming from the source, but each copy has a unique path from the source to the MP. After creating or updating a route to the source, the destination MP sends a unicast RREP back to the source. Intermediate MPs cannot generate RREPs by default, since the "Destination Only" (DO) flag is set to 1. Intermediate MPs create a route to the destination on receiving the RREP, and also forward the RREP toward the source. When the source receives the RREP, it creates a route to the destination.

\section{Related Work}

The original work using simulation models dates back to Broch et al. [13], members of the CMU monarch group. They evaluated four routing protocols, namely: The Dynamic Source Routing (DSR) [14], AODV, The Temporally-Ordered Routing Algorithm (TORA) [15], and the Dynamic Destination-Sequenced Distance-Vector Routing (DSDV) [16]. They focused their study on three metrics: packet loss, routing overhead, and route length. The same routing protocols have been compared later by Cano/Manzoni [8] on the perspective of energy consumption. The evaluation of these four protocols was carried out using Network Simulator-2 (NS2). Their main finding was that DSR and AODV perform better than DSDV, and clearly better than TORA. The mobility impact on energy conservation of the four previous routing protocols has been studied by Chen/Chang [17]. The result of this study was that reactive protocols are more speed-sensitive and proactive protocols not. However, in situations where nodes move in groups, on-demand protocols perform better than proactive ones in terms of energy conservation. Several works attempted to improve the energy consumption of distance vector-based routing protocols. The energy-aware AODV (EA-AODV) routing protocol has been proposed and compared to pure AODV in the perspective of the remaining energy by Gupta [18]. EA-AODV showed some improvement in energy consumption over the pure AODV. Another extension of AODV based on distributed minimum transmission (DMT) multicast has been proposed in [19]. The DMT-based EAODV routing protocol improves the energy consumption of pure AODV. Kim and Jang proposed New-AODV, an Enhanced AODV Routing Protocol, which attempts to extend the entire network lifetime by adjusting RREQ delay time [20]. Simulation on NS2 showed the superiority of New-AODV over the pure AODV routing protocol. A novel DSR-based energy-efficient routing algorithm has been proposed in [21]: Energy Dependent DSR (EDDSR). It has been compared with pure DSR, MDR and LEAR in a dense and sparse network scenario using the NS2 simulator. Their study showed first that MDR and EDDSR clearly outperform DSR in terms of node lifetime, especially in dynamic scenarios. In addition, this study revealed that the LEAR mechanism generates high-energy expenditure due to its route discovery process especially in dense networks. In [22] the Dynamic Packet 
Guidance (DPG) routing protocol is proposed. DPG uses route discovery and maintenance mechanisms just as in AODV. However, results of a simulation showed: DPG consumes less energy than AODV, DYMO, and DSR.

One of the first works comparing energy consumption between Optimized Link State Routing Protocol (OLSR) and DSR is found in [23]. They found that DSR takes advantage of its routing policy with a low traffic rate; however, when the traffic rate is higher, OLSR can perform better. Later, several works tried to improve the energy-efficiency of OLSR [24] [25].

Setty and Prasad compared three routing protocols namely: DSR, AODV, and OLSR in [26]. They varied the number of nodes between five and 15 on dynamic topologies with mobile nodes using Random Waypoint as mobility model. Results: AODV consumes most energy, followed by OLSR in transmission and receiving mode.

Cao in [27] provided a survey and analysis of energy related metrics used for ad hoc routing. He modified the default implementation of AODV in NS2 in order to obtain six other protocols: Minimum Total Transmission Power Routing (MTPR), Minimum Battery Cost Routing (MBCR), Min-Max Battery Cost Routing (MMBCR), Time Delay On-demand Routing (TDOD), Minimum Drain Rate (MDR), and Conditional Max-Min Battery Capacity Routing (CMMBCR). The result revealed that MTPR in general can find the minimum energy cost path and can conserve energy compared to other protocols.

Kafhali et al. in [28] compared the energy consumption of the protocols AODV, DSR and DSDV under three mobility models (Random Waypoint Model, Reference Point Group Model, and Manhattan Grid Model) and three traffic models (CBR, Pareto, and Exponential). The simulation considered the total consumed energy in joule spent in transmitting and receiving the control packets. The main outcome is that AODV consumes more energy compared to DSR and DSDV with CBR traffic. In contrary, with Pareto and Exponential traffics AODV consumes the least energy.

Maan and Mazhar evaluated the performance of five routing protocols, namely AODV, DSR, DSDV, OLSR, and DYMO (Dynamic MANET on demand) with regard on mobility models [29]. They considered important metrics such as delay, PDR, and normalized routing load; but they did not consider energy. One of the main results is the proposed matrix for selection of routing protocols in terms of mobility models and performance parameters.

Two energy performance metrics have been used in [30] in order to compare AODV and DSR: the routing energy consumption and the average energy consumption. The overall results show a better performance of DSR over AODV except in static networks or for low loads.

More recently, there has been an emphasis on comparing reactive, proactive and hybrid routing protocols. But almost all works were focus on well-known performance metrics such as end-to-end delay [31] [32], throughput [31] [32] [33], and PDR [31] [33]. One of the few works considering energy is found in 
[9]. Besides considering the throughput and the delay in static and mobile scenario, the authors also considered the remaining energy on a node. But all nodes in the networks do not have the same energy consumption scheme. Therefore, this metric cannot really help to appreciate the impact of a routing protocol on the energy consumption of the whole network. To the best of our knowledge, none of the previous works has deeply compared HWMP, OLSR, and AODV with regard on energy consumption.

\section{Simulation Set-Up}

We made use of Network Simulator (NS) version 3.25 to compare the three routing protocols. Network Simulator is reportedly [34] one of the better performing simulation tools available.

\subsection{Energy Consumption Model in NS3}

The NS-3 Energy Framework is composed of two parts: Energy Source and Device Energy Model.

The Energy Source represents the power supply on each node. A node can have one or more energy sources, and each energy source can be connected to multiple device energy models. Connecting an energy source to a device energy model implies that the corresponding device draws power from the source. The basic functionality of the Energy Source is to provide energy for devices on the node. When energy is completely drained from the Energy Source, it notifies the devices on node such that each device can react to this event.

The Device Energy Model is the energy consumption model of a device on node. It is designed to be a state-based model where each device is assumed to have a number of states, and each state is associated with a power consumption value. The corresponding Device Energy Model will notify the Energy Source of the new current draw of the device, whenever the state of the device changes. The device energy model used in this work is the WIFI radio energy model. In this model, four states are defined for the radio: TX for transmit, RX for receive, IDLE for idle, and SLEEP for sleep. The default state is IDLE.

Default values of the above attributes are based on measurements reported in [35]. In our case we assumed in the different scenarios that each node was equipped with a PRO/Wireless 3945ABG $802.11 \mathrm{a} / \mathrm{b} / \mathrm{g}$ network card. Thanks to the specification document of this network card [36], we were able to set the values of the energy model attributes to obtain a better realistic simulation environment.

HWMP works only with mesh devices. A mesh device according to the NS3 definition is a special type of device that can possess multiple WIFI interfaces. It is not possible to directly evaluate the energy consumption of a mesh device using the NS3 energy module. So, the definition of a function that will extract all WFI devices found on the mesh device before evaluating the energy consumption was imperative. 
HWMP works only with mesh devices. A mesh device according to NS3 definition is a special type of device that can possess multiple WIFI interfaces. It is not possible to directly evaluate the energy consumption of a mesh device using NS3 energy module. So, the definition of a function that will extract all WFI devices found on the mesh device before evaluating the energy consumption was imperative.

\subsection{Particularisation of Routing Protocols}

We modified some values of the routing protocols' attributes in order to guarantee a fair evaluation. Table 1 provides the different modifications on routing protocols.

No root node has been set for HWMP since it is working in reactive mode. The rest of attributes have been left with their default values as presented in NS3 doxygen [37].

\subsection{Network Topology and Node Connexions}

Nodes are distributed on a disc surface area with different radius in our scenarios. The radius chosen for the different scenarios resulted from the tests we carried out to guarantee fairness in the performance evaluation of the different routing protocols. Three numbers of nodes are defined: 16, 49, and 100. A basic overview of the random nodes placement within the disc area with 49 nodes is given in Figure 1. The communication between the nodes is established randomly.

Table 1. Customization of routing protocols.

\begin{tabular}{|c|c|c|c|}
\hline Protocol & Attribute & Description & Value \\
\hline \multirow{5}{*}{ AODV } & HelloInterval & HELLO messages emission interval & $3 \mathrm{sec}$ \\
\hline & RreqRetries & $\begin{array}{l}\text { Maximum number of retransmissions of RREQ } \\
\text { to discover a route }\end{array}$ & 5 \\
\hline & ActiveRouteTimeout & $\begin{array}{l}\text { Period of time during which the route is } \\
\text { considered to be valid }\end{array}$ & 100 \\
\hline & AllowedHelloLoss & $\begin{array}{l}\text { Number of hello messages which may be lost for } \\
\text { valid link }\end{array}$ & 20 \\
\hline & DestinationOnly & $\begin{array}{l}\text { Indicates only the destination may respond to a } \\
\text { RREQ }\end{array}$ & True \\
\hline \multirow[t]{3}{*}{ OLSR } & HelloInterval & HELLO messages emission interval & $3 \mathrm{sec}$ \\
\hline & RandomStart & Random delay at first proactive PREQ & $0.1 \mathrm{sec}$ \\
\hline & UnicastPreqThreshold & $\begin{array}{l}\text { Maximum number of PREQ receivers, when a } \\
\text { PREQ is sent as a chain of unicasts }\end{array}$ & 10 \\
\hline \multirow[t]{3}{*}{ HWMP } & UnicastDataThreshold & $\begin{array}{l}\text { Maximum number of broadcast receivers, when } \\
\text { a broadcast is sent as a chain of unicasts }\end{array}$ & 5 \\
\hline & DoFlag & Destination only HWMP flag & True \\
\hline & RfFlag & Reply and forward flag & False \\
\hline
\end{tabular}




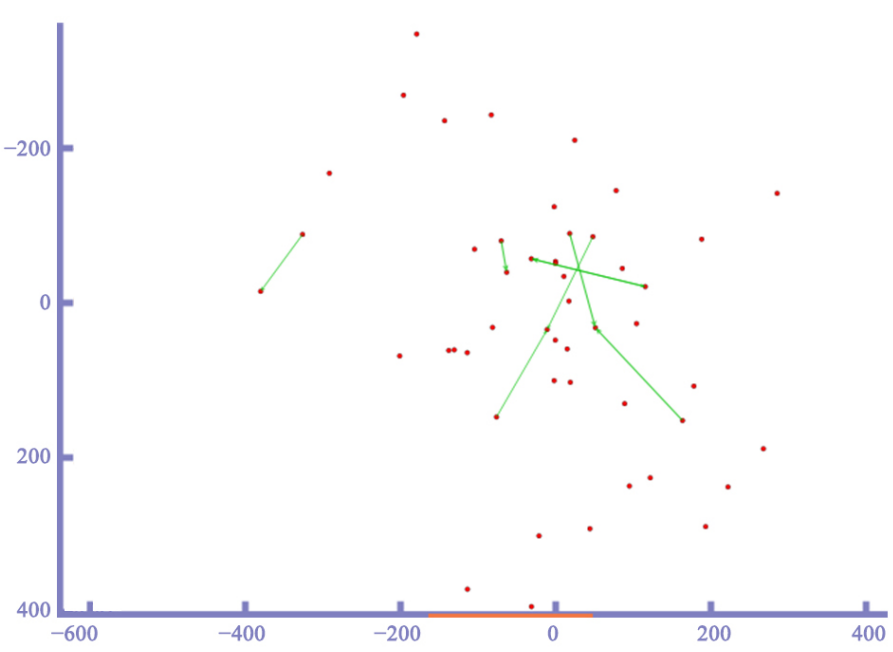

Figure 1. Topology with 49 nodes with some connections.

The source and destination nodes are chosen randomly thanks to the uniform random variable implemented in NS3 as well as the duration of the connections between nodes. The connections present a uniform arrival distribution with duration generated by an exponential variable with a mean of 30 seconds. Using these parameters we can be sure that with a 180 seconds simulation, several connections will overlap.

\subsection{Mobility and Propagation Loss Models}

\subsubsection{Mobility Model}

We used two mobility models to be more realistic. We evaluated firstly the routing protocols with fixed-location nodes. The mobility model used in NS3 for making the node to remain static is the Constant Position Mobility Model. We used secondly Random Waypoint Mobility Model for our mobile scenarios. In this model, each node starts by pausing at time zero. After pausing, the object will pick a new waypoint and a new random speed, and will begin moving towards the waypoint at a constant speed. When it reaches the destination, the process starts over.

\subsubsection{Propagation Loss Model}

A propagation loss model enables to simulate the loss of power or the attenuation of a signal passing through a transmission channel. It helps to calculate the reception power of a destination node. This enables to determine whether the node can receive a signal. The value of the reception power depends on the emission power of the source node and the position of the source and the destination node. The position of nodes depends on the implemented mobility modes. We adopt the Log-distance Propagation Loss Model. This model calculates the reception power as given in Equation (1):

$$
P L=P L_{0}+10 n \log _{10}\left(d / d_{0}\right)
$$

$n$ : the path loss distance exponent;

$d_{0}$ : reference distance $(\mathrm{m})$; 
$P L_{0}$ : path loss at the reference distance $(\mathrm{dB})$;

$d$ : distance (m);

$P L$ : path loss $(\mathrm{dB})$.

When the path loss is requested at a distance smaller than the reference distance, the Tx power is returned. The default reference loss of $46.6777 \mathrm{~dB}$ corresponds to reference distance of one meter [37].

\subsection{Summary of Simulation Parameters}

Table 2 contains a summary of the parameters used to carry out the simulations.

\section{Results and Discussion}

This section aims to provide and discuss the results of the simulations. It is divided into two parts. The first part focuses on the energy consumed by each routing protocol in different network sizes and transmission rates, and using different radio types. The second part tries to determine the efficiency of the energy consumption with regard on throughput and PDR.

Table 2. Summary of simulation parameters.

\begin{tabular}{|c|c|}
\hline Parameters & NS3 values \\
\hline Topology & Randomly distributed in a $3.14^{\star}$ Radius ${ }^{\star}$ Radius $\mathrm{m}^{2}$ region \\
\hline Mobility Model & $\begin{array}{c}\text { Constant Position Mobility Model/Random Waypoint } \\
\text { Mobility Model }\end{array}$ \\
\hline Number of nodes & 16,49 and 100 \\
\hline Radio type & $802.11 \mathrm{a} / \mathrm{b} / \mathrm{g}$ \\
\hline MAC protocol & $802.11 \mathrm{~s}$ \\
\hline Propagation loss model & Log-distance Propagation Loss Model \\
\hline Propagation delay model & Constant Speed Model \\
\hline Routing protocol & AODV/HWMP/OLSR \\
\hline Transport protocol & UDP \\
\hline Packet size & 1024 [bytes] \\
\hline Transmission rate & $100 / 200 / 300 / 400[\mathrm{Kbps}]$ \\
\hline Number of connection & Equal to number of nodes \\
\hline Connection arrival distribution & Random \\
\hline Data mode & $\begin{array}{c}\text { Of dm Rate } 6 \text { Mbps/Dsss Rate 5_5 Mbps /Erp of dm Rate } 6 \\
\text { Mbps }\end{array}$ \\
\hline Duration of each connection & Exponential $($ mean $=30 \mathrm{~s})$ \\
\hline Traffic type & CBR \\
\hline Transmission current & $0.6[\mathrm{~A}]$ \\
\hline Receiving current & $0.467[\mathrm{~A}]$ \\
\hline Simulation time & $180[\mathrm{sec}]$ \\
\hline
\end{tabular}




\subsection{Energy Consumption}

Table 3 gives the average energy consumption in different scenarios. This table is obtained by averaging the energy consumption for each routing protocol, for each transmission rate and the number of nodes. The detailed results of 216 simulations are provided in Appendix A.

\subsubsection{Constant Position}

\subsection{1a}

The simulation results of the energy consumption for $802.11 \mathrm{a}$ in a static position are plotted in Figure 2. From this figure, it is easy to notice that OLSR is the highest energy consumer. According to Table 3, the second routing protocol with the highest energy consumption is AODV, and HWMP being the last. This table also reveals that the difference in energy consumption between HWMP and OLSR is far higher than the one between AODV and HWMP. This is because OLSR is a proactive routing protocol while HWMP is a hybrid one but working in the reactive mode. While OLSR tries to keep its routing table up to date during the entire simulation time, HWMP keeps the information only about the active route and this goes the same for AODV. Since HWMP and AODV apply the same routing approach, the slight difference in their energy consumption results from the fact that AODV is a layer three routing protocol while HWMP is a layer two routing protocol.

Table 3. Average energy consumption in different scenarios in joules.

\begin{tabular}{ccccccc}
\hline \multirow{2}{*}{ Standard } & \multicolumn{3}{c}{ Constant } & \multicolumn{3}{c}{ Mobile } \\
\cline { 2 - 7 } & AODV & HWMP & OLSR & AODV & HWMP & OLSR \\
\hline $802.11 \mathrm{a}$ & 3719 & 3362 & 4591 & 3500 & 3859 & 4069 \\
$802.11 \mathrm{~b}$ & $\mathbf{3 0 6 8}$ & 3822 & 3245 & 3098 & 4012 & 2507 \\
$802.11 \mathrm{~g}$ & 2953 & 3604 & 3454 & 2693 & 3616 & $\mathbf{2 4 2 0}$ \\
\hline
\end{tabular}

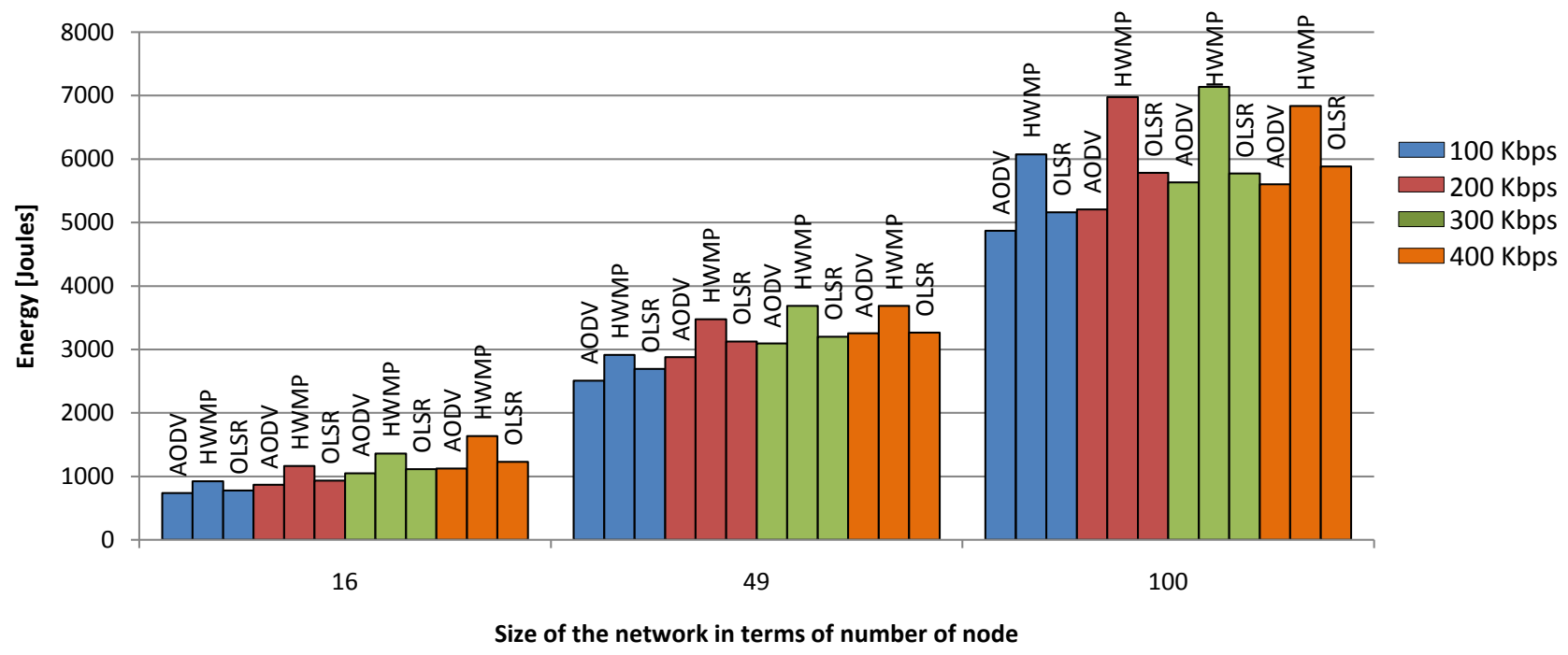

Figure 2. Energy consumption for 802.11a in static position. 
$802.11 b$

Figure 3 depicts the energy consumption when nodes are equipped with an 802.11b network card. In all scenarios, it is obvious that HWMP is the highest energy consumer. The energy consumption of OLSR is similar to the one of AODV in small network sizes. But the energy consumption of OLSR is slightly greater when the size of the network increases. From Table 3, based on an average estimation, OLSR consumes more energy than AODV. This observation confirms the result about the remaining energy of a node in [9]. The noticeable difference in energy consumption between AODV and HWMP is mainly caused by the peer link management mechanism. This mechanism enables each meshed point to discover and track neighboring nodes. Thus beyond the fact that HWMP is a layer two routing protocol, when there is a high number of collision between the management frames, there is an amount of energy consumed for the retransmission of those frames.

\section{$802.11 \mathrm{~g}$}

Figure 4 shows: except in the case of 49 nodes and at $200 \mathrm{kbps}$, HWMP has the highest energy consumption. Similar to the case of $802.11 \mathrm{~b}$, AODV and OLSR present just a slight difference in energy consumption in constant position. Globally from Table 3, HWMP is the protocol, which consumes the most energy. The reason is the same as the one mentioned in the case of $802.11 \mathrm{~b}$. In the particular case of 49 nodes and with the same condition as in $802.11 \mathrm{~b}$, to examine how the change in standard can influence the energy consumption, the average energy consumed at $100 \mathrm{kbps}$ for $802.11 \mathrm{~b}$ and $802.11 \mathrm{~g}$ is provided in $\mathrm{Ta}$ ble 4.

Table 4 reveals that under the same conditions, the change of the 802.11 standard induces an increase in the energy consumption. This means it is not always the standard with the longer transmission range that will consume the higher amount of energy. In other words, the modulation of each standard also influences the energy consumption.

\subsubsection{Mobile Position}

The below scenarios have enabled us to bring out the influence of mobility on energy consumption.

802.11a

Figure 5 shows: the mobility of nodes causes an important fluctuation in energy consumption. AODV seems to consume less energy than others. This confirms the results in [17]. Contrariwise, it is not easy to observe between HWMP and OLSR, which is consuming less. However, it is clear that OLSR is the highest energy consumer in this mobile scenario (Table 3). This is because the movement of nodes leads to more route updates. When considering the average energy consumption for mobile and static scenarios, we notice that HWMP experiences a rise while AODV and OLSR experience a fall. The fall of AODV and OLSR is justified by the fact that the movement of nodes causes a lot of lost packets. The energy used for the reception of packets is therefore no 


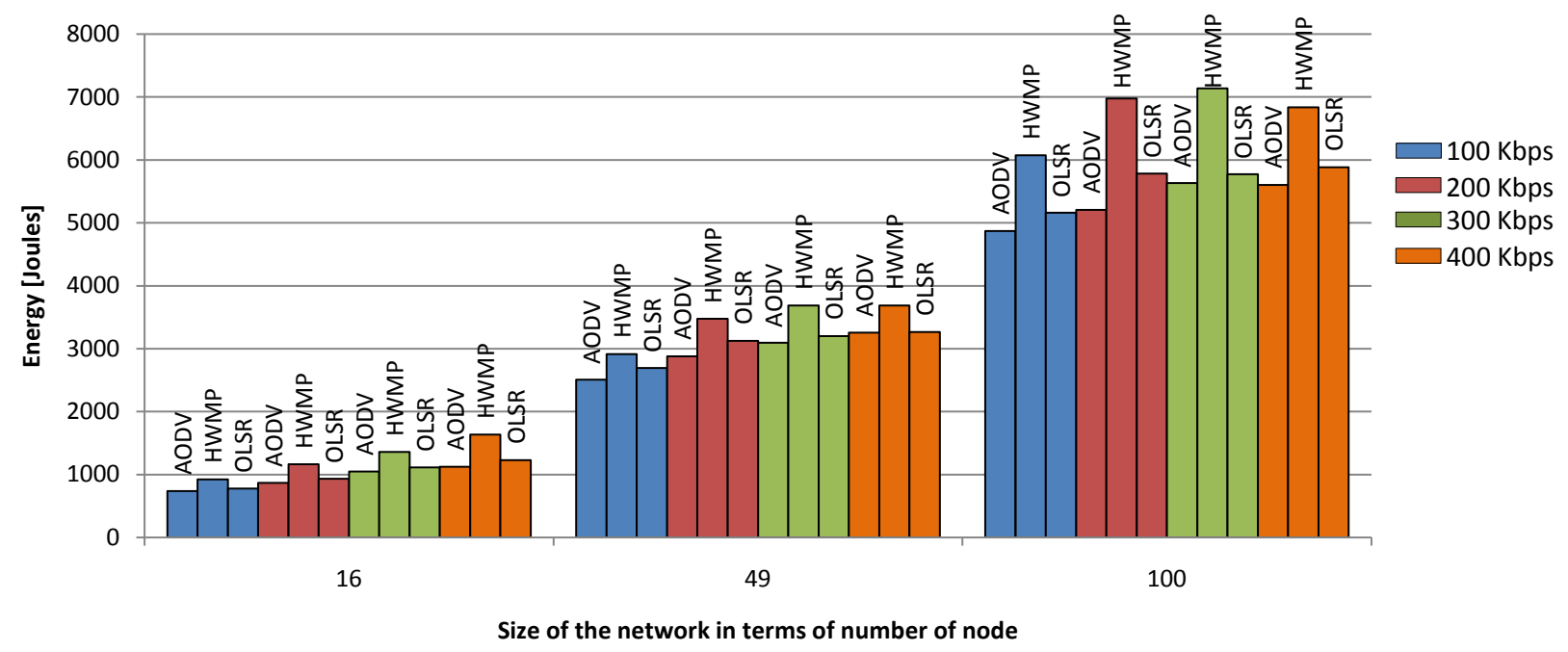

Figure 3. Energy consumption for $802.11 \mathrm{~b}$ in static position.

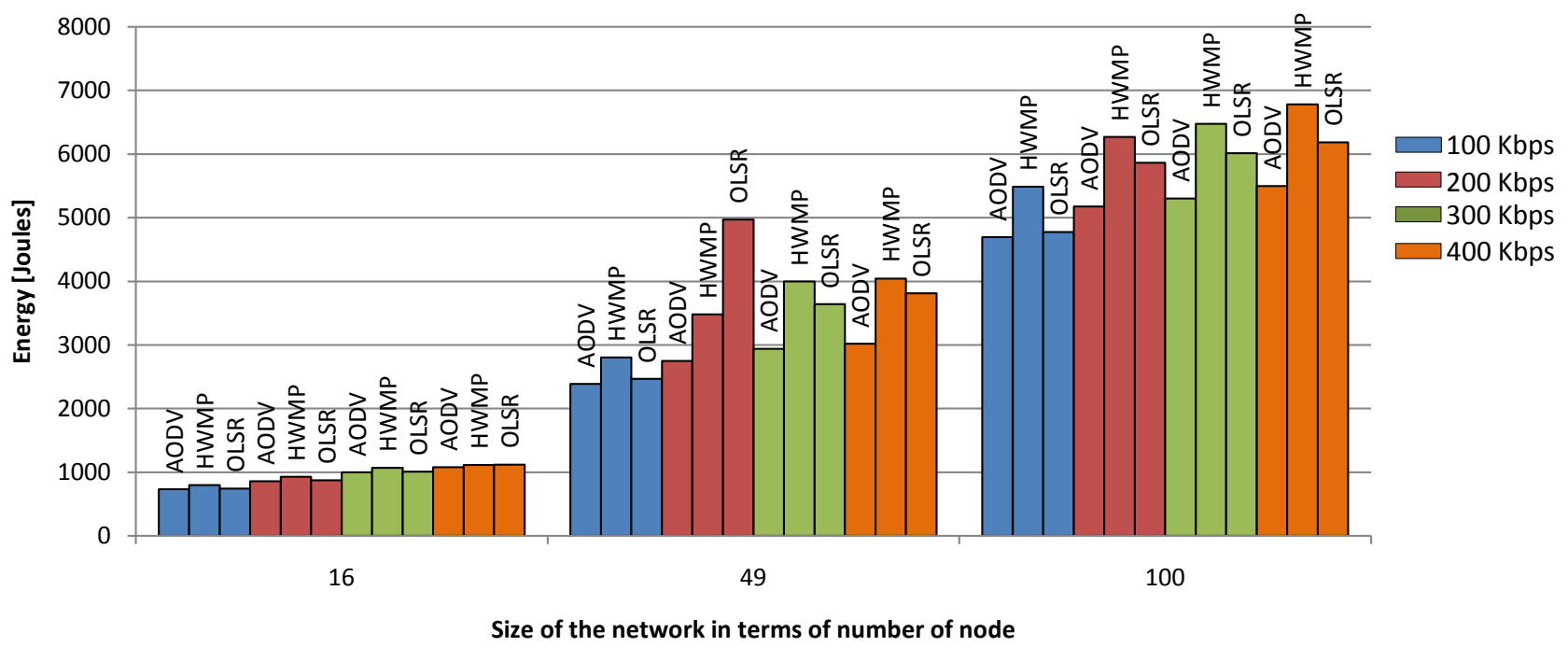

Figure 4. Energy consumption for $802.11 \mathrm{~g}$ in static position.

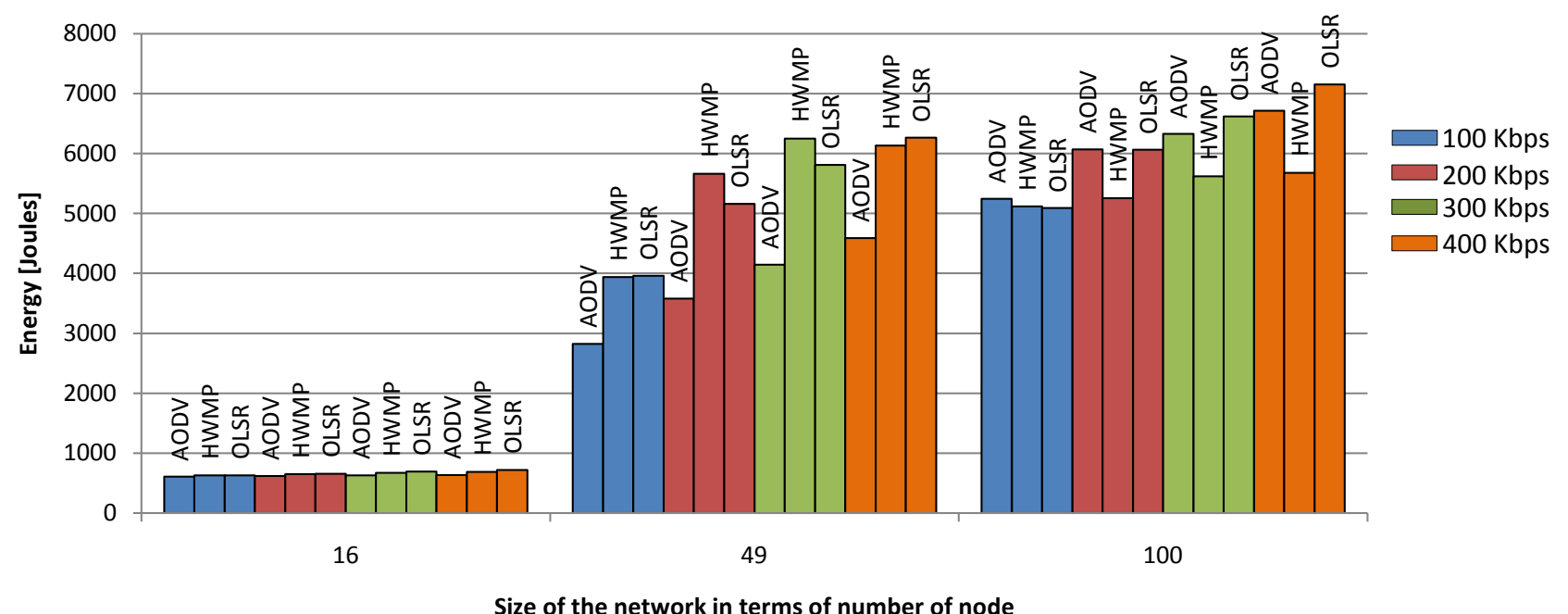

Figure 5. Energy consumption for 802.11a in mobile position. 
Table 4. Energy consumption at $100 \mathrm{kps}$ for $802.11 \mathrm{~b}$ and $802.11 \mathrm{~g}$ in joules.

\begin{tabular}{cccc}
\hline Constant position & AODV & HWMP & OLSR \\
\hline $802.11 \mathrm{~b}$ & 2507 & 2913 & 2694 \\
$802.11 \mathrm{~g}$ & 2390 & 2804 & 2467 \\
\hline
\end{tabular}

longer counted. In the case of HWMP, the increase in energy consumption is caused mainly by its nature (Layer 2 routing protocol) and the peer management system. In fact, the movement of nodes heavily affects the peer management system applied in HWMP. Peers are formed dynamically based on their position. The airtime link metric (ALM) used as metric with HWMP is very affected by the error rate introduced by the movement of nodes. HWMP broadcasts more messages in such scenarios than AODV and OLSR.

\section{$802.11 b$}

In almost all cases according to Figure 6, the energy consumption of HWMP is far above that of AODV and OLSR. Figure 6 also shows that AODV is highly affected in the 49 nodes scenario. Its energy consumption has increased from $2183 \mathrm{~J}$ at $100 \mathrm{kbps}$ to $5551 \mathrm{~J}$ at $400 \mathrm{kbps}$. Since it is the same mobility pattern, which is applied at a different transmission rate, it becomes obvious that in a scenario where the nodes are mobile the transmission rate can highly influence the energy consumption of AODV.

Table 3 reveals the fact that in this mobile scenario, HWMP has globally the highest energy consumption and OLSR the lowest. We also observe that between static and mobile scenarios, AODV and HWMP have experienced a slight increase in their energy consumption; while the energy consumed with OLSR has reduced. For both AODV and HWMP, the broadcast of RREQ messages for broken roads or paths is the reason of the slight increase in energy consumption. Moreover, the peer management system is another reason, which justifies the increase in energy consumption with HWMP.

\section{$802.11 g$}

HWMP consumes more energy than AODV and OLSR for all mobile scenarios with $802.11 \mathrm{~g}$ according to Figure 7 . AODV and OSLR have very close energy consumption in almost all scenarios except in case of 100 nodes at 100 kbps. A general evaluation in their energy consumption can be done thanks to Table 3. From this table, it is clear that globally OLSR has the lowest energy consumption. The reasons for increase or decrease in energy consumption are the same as explained in case of 802.11a and $802.11 \mathrm{~b}$. However, the average energy consumed by HWMP in both mobile and static scenarios is almost the same. So in this case, the mobility of nodes has not a strong impact on the energy consumption as far as HWMP is concerned. As in the case of a constant position, a focus can be done on the scenario of 49 nodes for $802.11 \mathrm{~b}$ and $802.11 \mathrm{~g}$ under the same conditions. Table 5 enables to really appreciate the impact of 802.11 standards on energy consumption. The highest energy consumed with $802.11 \mathrm{~g}$ is lower than $4000 \mathrm{~J}$ while with $802.11 \mathrm{~b}$ it is above $5000 \mathrm{~J}$. 


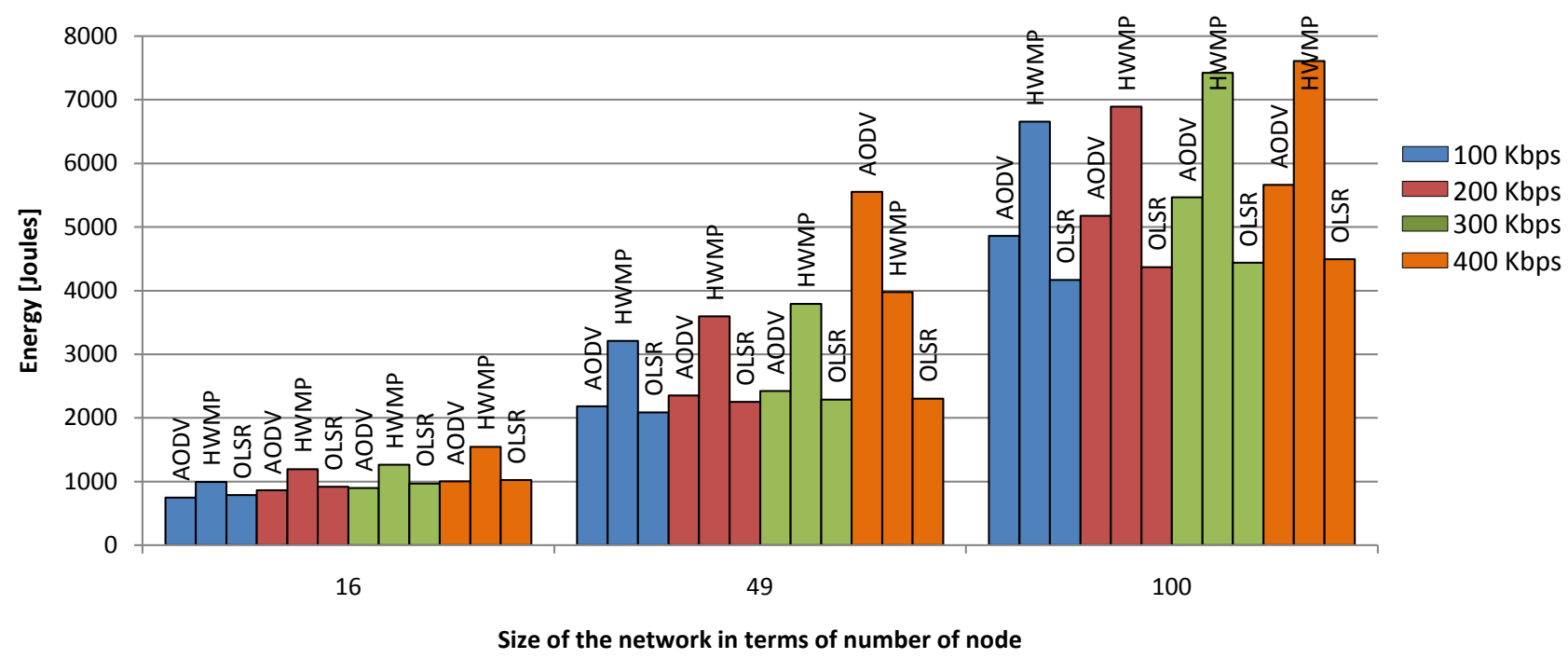

Figure 6. Energy consumption for $802.11 \mathrm{~b}$ in mobile position.

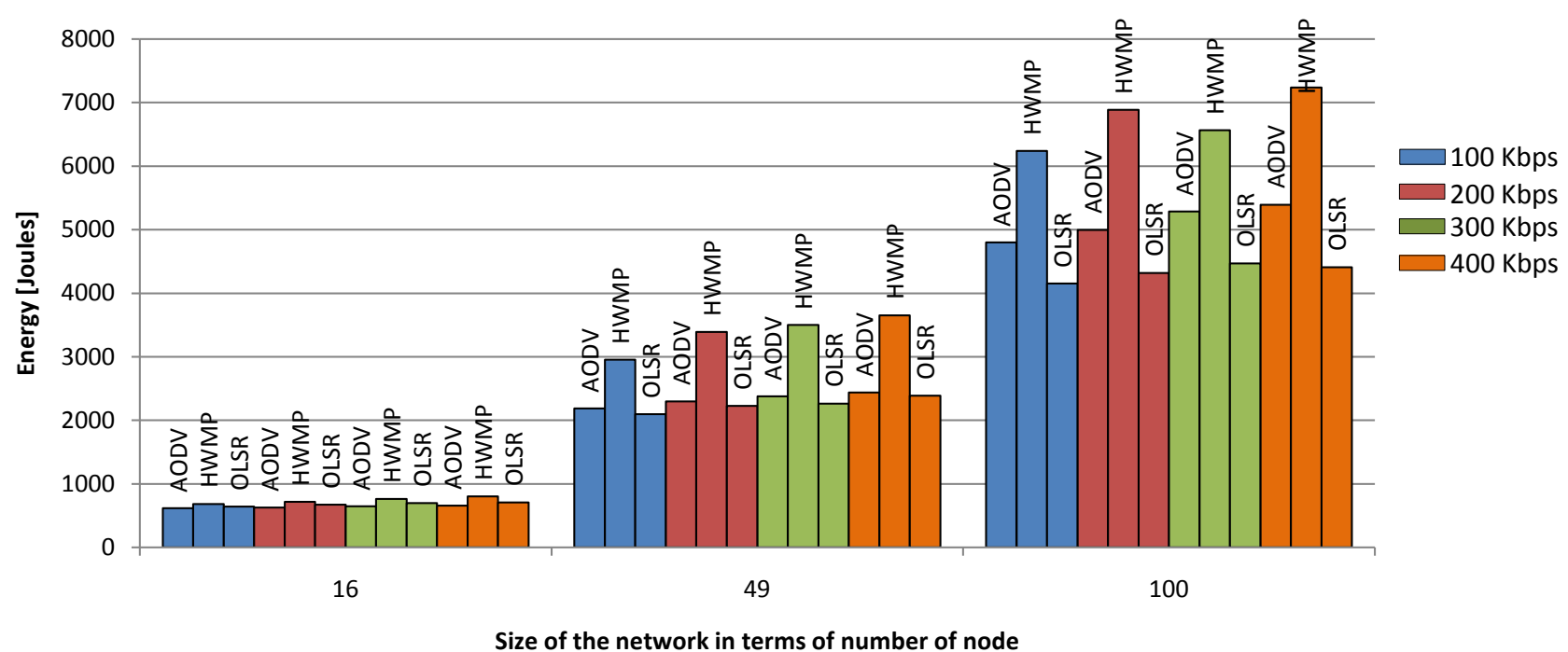

Figure 7. Energy consumption for $802.11 \mathrm{~g}$ in mobile position.

Table 5. Energy consumption at $400 \mathrm{kps}$ for $802.11 \mathrm{~b} / \mathrm{g}$ in mobile scenario of 49 nodes.

\begin{tabular}{cccc}
\hline Mobile position & AODV & HWMP & OLSR \\
\hline $802.11 \mathrm{~b}$ & 5551 & 3976 & 2303 \\
$802.11 \mathrm{~g}$ & 2436 & 3650 & 2386 \\
\hline
\end{tabular}

In addition, changing from $802.11 \mathrm{~g}$ to $802.11 \mathrm{~b}$ can double the energy consumption with a protocol like AODV under the same conditions. Finally, the proactive routing protocol is less affected by the change of the 802.11 standard.

\subsection{Energy Consumption}

Considering only the energy consumption of a routing protocol without paying attention to other characteristics can bias the conclusion. The aim here is to evaluate how efficient is the use of energy. Two metrics are therefore introduced: 
e-PDR and e-Throughput.

\subsection{1. e-PDR}

We define the e-PDR as the ratio between the energy consumed and the packets delivery ratio. It is given in Equation (2).

$$
e-P D R=E C / P D R
$$

$E C$ : Energy consumed;

PDR: Packet Delivery Ratio.

This performance metric enables to know, which protocol has the best ratio Energy consumed/ delivered Packets. The protocol with the smallest value in e-PDR is therefore the best energy-efficient protocol in the point of view of PDR.

\subsection{2. e-PDR}

We define the e-Throughput as the ratio between the energy consumed and the throughput in Equation (3). This metric is similar to the energy expenditure defined in [38].

$$
e-\text { Throughput }=E C / \text { Throughput }
$$

$E C$ : Energy consumed.

This performance metric enables us to evaluate, which protocol has the best ratio Energy consumed/Throughput. The protocol with the smallest value in e-Throughput is therefore the best energy-efficient protocol in point of view of throughput.

\subsubsection{Constant Position}

\subsection{1a}

Figure 8 and Figure 9 depict respectively the e-PDR and e-Throughput for the different scenarios when using the 802.11a standard in constant position. OLSR is the protocol that provides the smallest e-PDR and e-Throughput for the 16 nodes network. It means that OLSR is the protocol that consumes energy most efficiently for the delivery with the best data rate. It is followed by AODV. OLSR and AODV have almost the same energy-efficiency in terms of e-PDR in a network with 49 nodes at a low transmission rate $(100 \mathrm{kbps})$. Figure 9 shows that AODV and OLSR have the same energy-efficiency as far as the transmission data rate is concerned. Figure 8 shows: the three protocols offer almost the same energy-efficiency in terms of e-PDR between transmission rates of $200 \mathrm{kbps}$ and 300 kbps. However, AODV offers the best energy-efficiency in terms of e-Throughput when we consider Figure 9. OLSR offers the best energy-efficiency in terms of e-PDR followed by AODV at a higher transmission rate (400 kbps). For scenarios with 100 nodes it is very obvious for the e-PDR that OLSR is the best energy-efficient routing protocol followed by AODV. However, Figure 9 shows that except at $100 \mathrm{kpbs}$ where OLSR outperforms AODV, the rest of the scenarios is dominated by AODV. It comes globally that HWMP has the worst energy-efficiency, despite the fact that it has the lower energy consumption in average. 


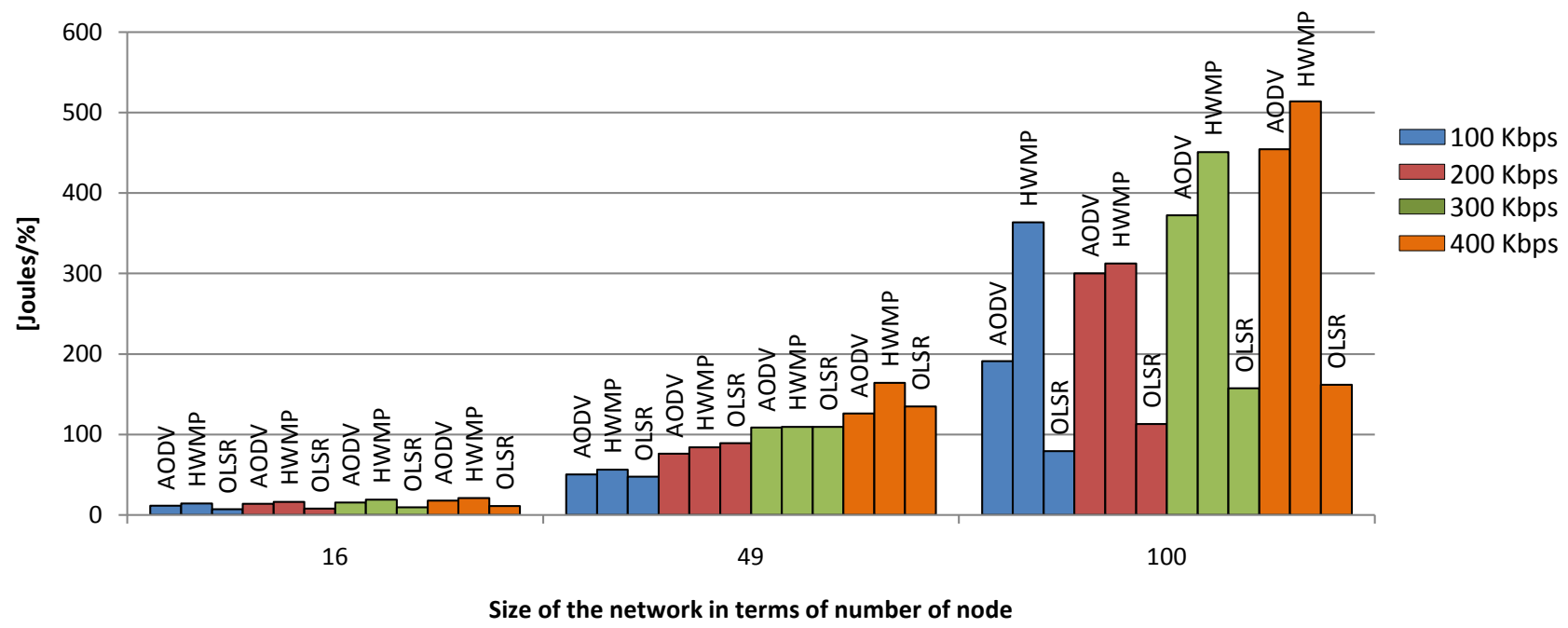

Figure 8. e-PDR for 802.11a in constant position.

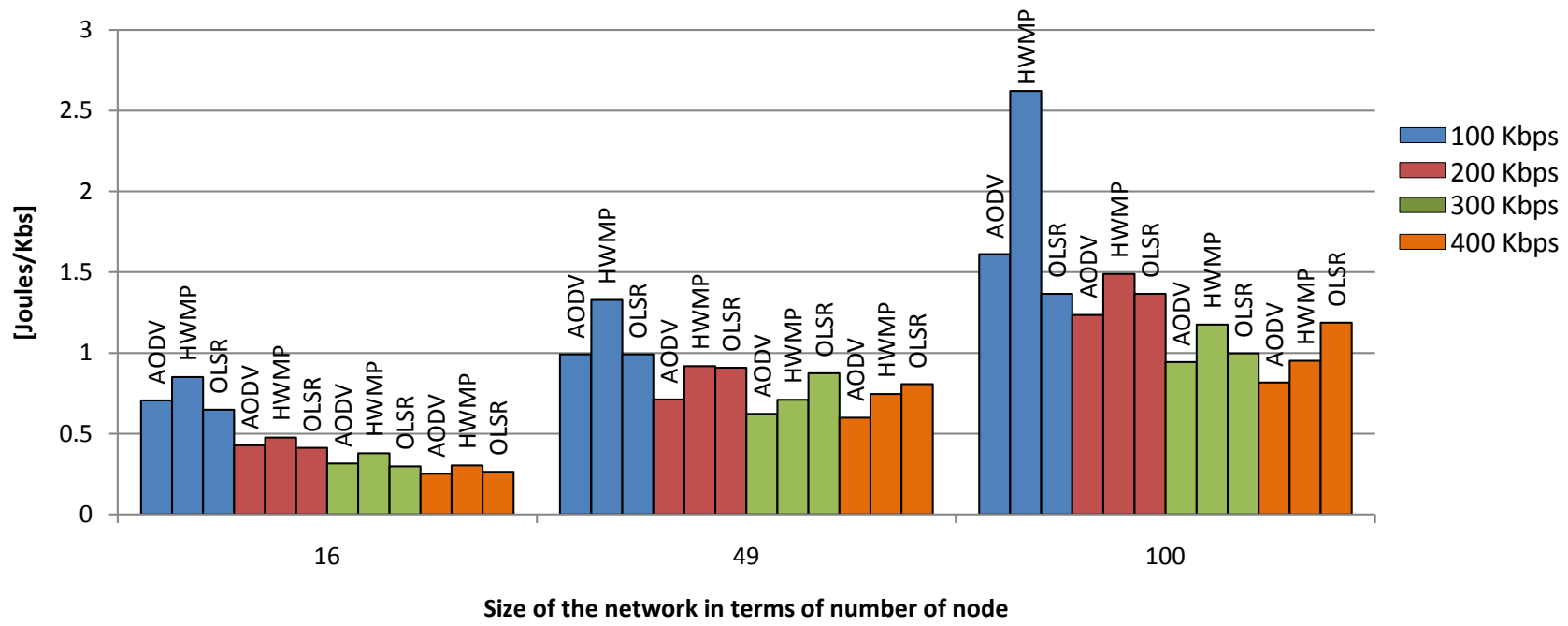

Figure 9. e-Throughput for 802.11a in constant position.

\section{$802.11 b$}

Figure 10 shows that for a network of 16 nodes, all protocols have almost the same performance. OLSR offers the best performance in terms of e-PDR for the 49 and 100 nodes network. Regarding the e-Throughput depicted in Figure 11, AODV outperforms the other protocols. However, considering the throughput alone, the superiority of AODV does not always hold. It is verified for a high number of nodes. In a small scale such as 16 nodes, we found that HWMP is providing a better throughput than the other protocols in a static scenario, as presented in Appendix 1. So the work in [9], where Matsuo et al. used a 48 nodes' network and found that HWMP provides the worst throughput cannot be generalized.

802.11g

Figure 12 and Figure 13 depict respectively the e-PDR and e-Throughput for scenarios in which nodes are equipped with $802.11 \mathrm{~g}$ radios. Figure 12 shows 


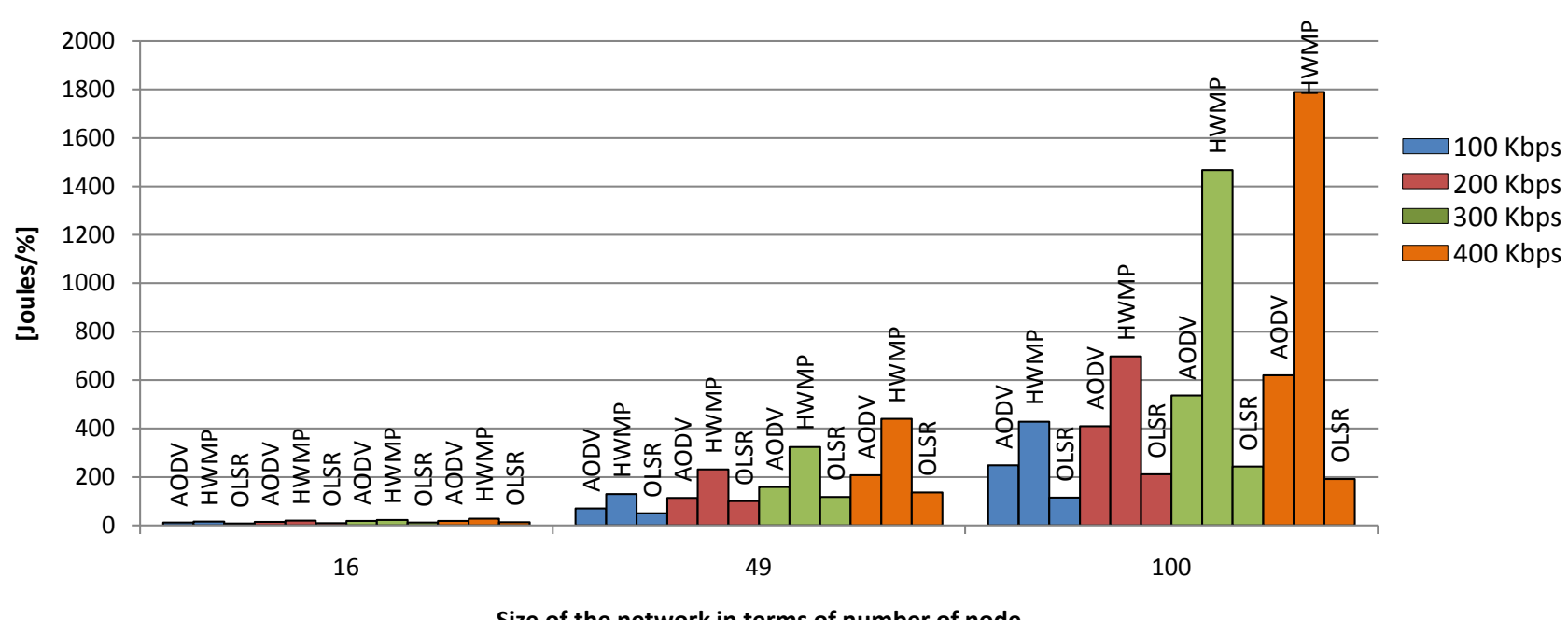

Figure 10. e-PDR for $802.11 \mathrm{~b}$ in constant position.

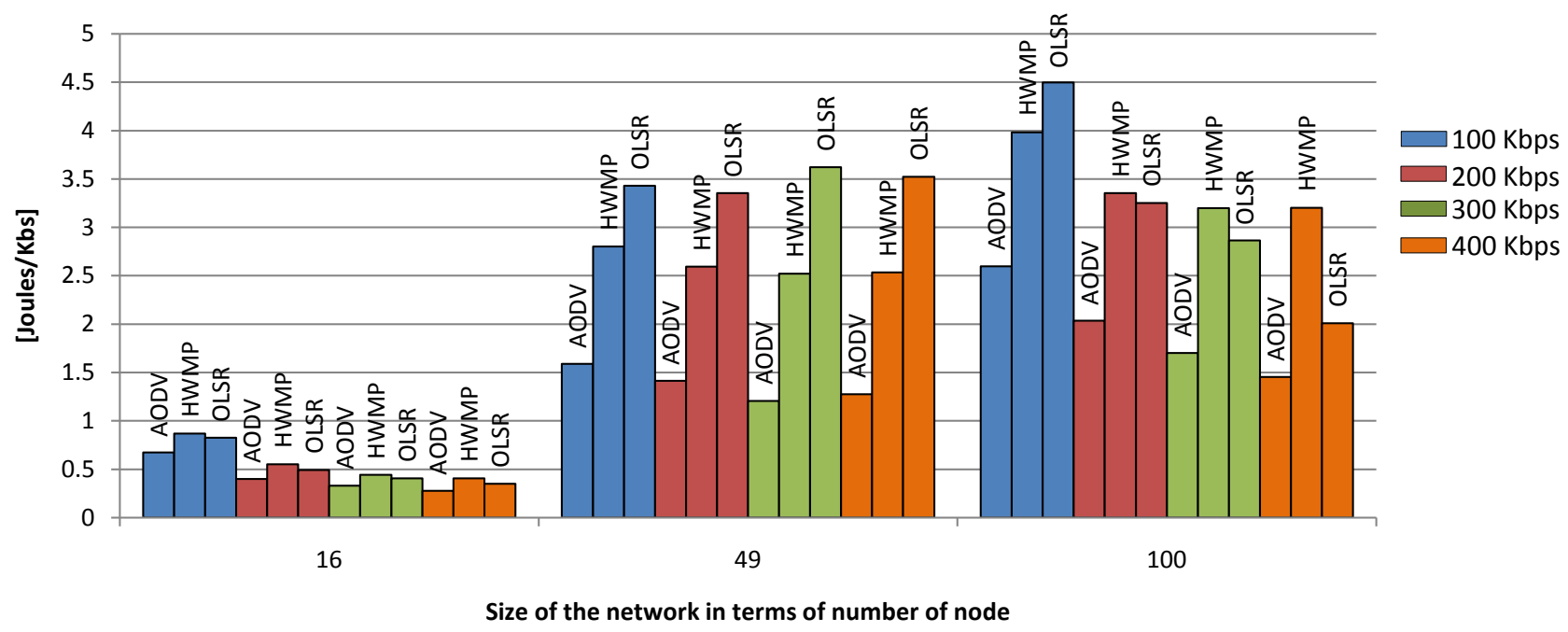

Figure 11. e-Throughput for $802.11 \mathrm{~b}$ in constant position.

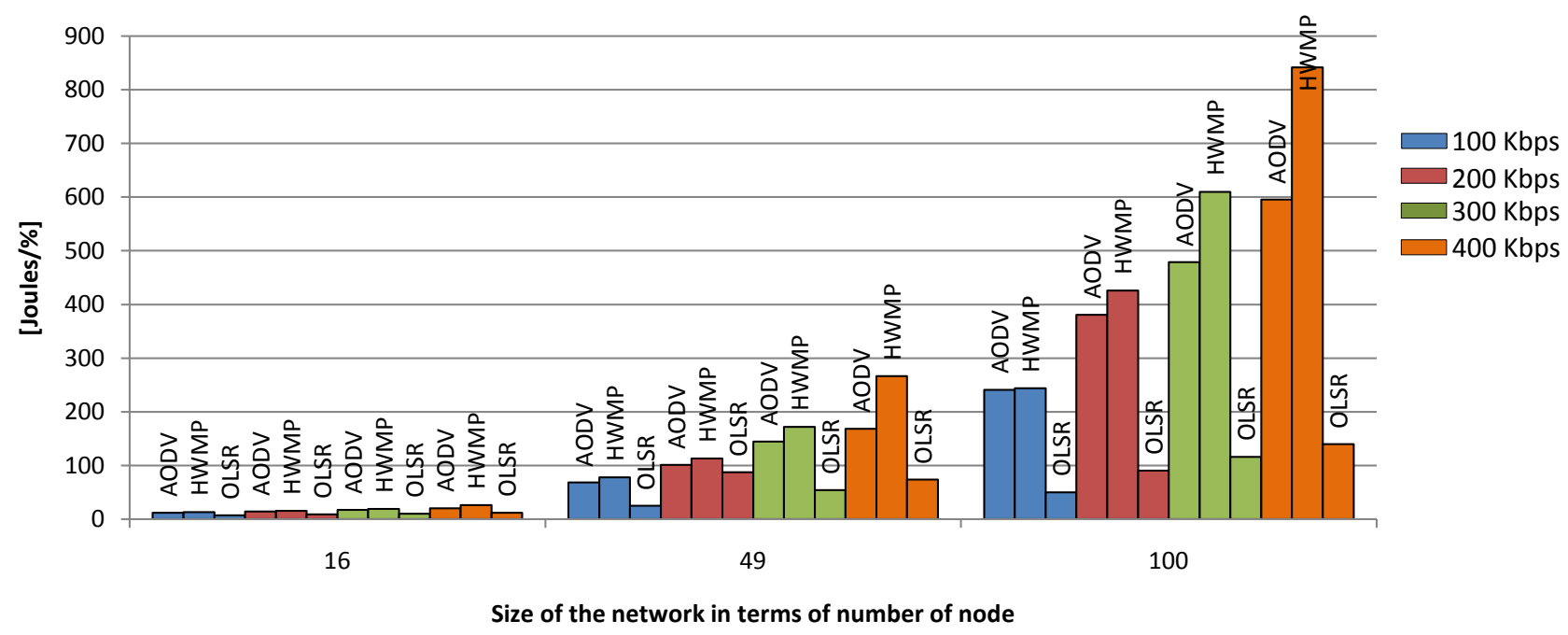

Figure 12. e-PDR for $802.11 \mathrm{~g}$ in constant position. 


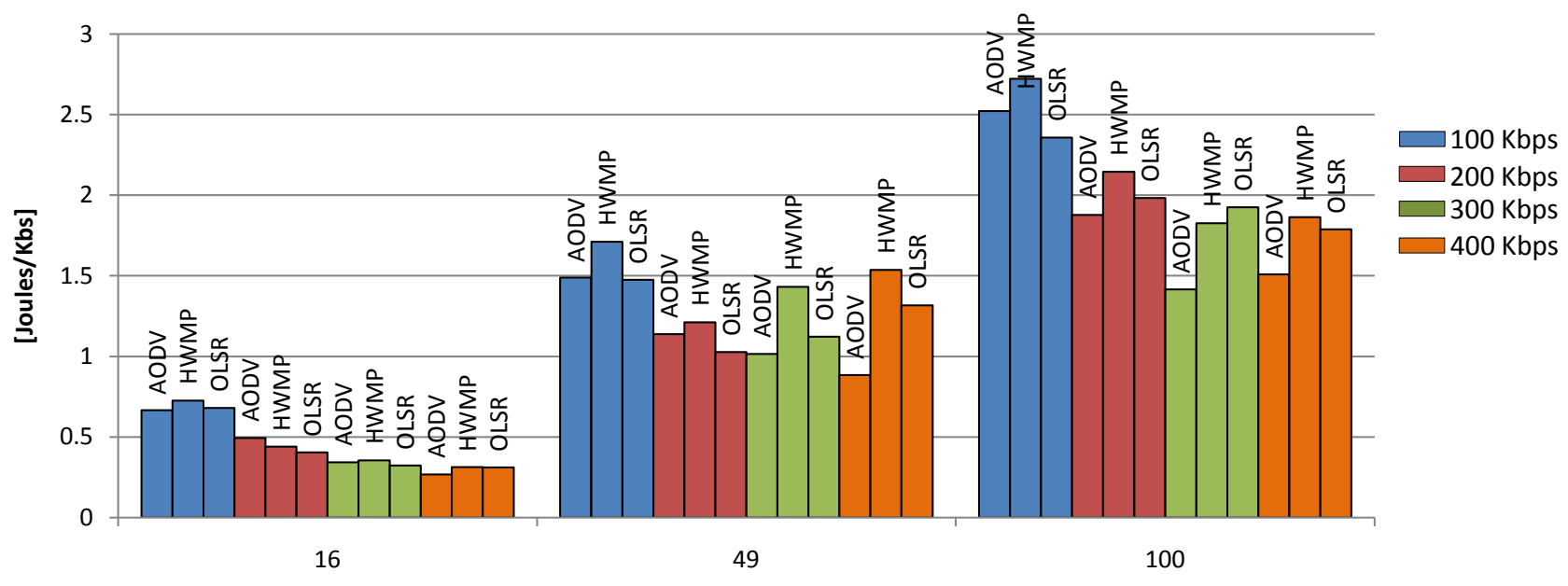

Size of the network in terms of number of node

Figure 13. e-Throughput for $802.11 \mathrm{~g}$ in constant position.

from every indication that OLSR offers the best e-PDR in all scenarios, followed by AODV. Regarding the e-Throughput, the performances depend on the number of nodes in the network. In the 16 nodes network, at 100, 200 and $300 \mathrm{kbps}$, OSLR is globally the most energy-efficient; but at $400 \mathrm{kbps}$ AODV performs better. The network with 49 nodes shows very fluctuating performances of the routing protocols according to the transmission rates. AODV and OLSR have the same performance at $100 \mathrm{kbps}$. OLSR outperforms AODV at $200 \mathrm{kbps}$. AODV has the best performance at $300 \mathrm{kbps}$ and $400 \mathrm{kbps}$. For the 100 nodes network except in case of $100 \mathrm{kbps}$ where OLSR outperforms all other protocols, AODV is globally the best choice for a transmission rate above $200 \mathrm{kbps}$.

As a general observation, OLSR offers the best performances in terms of e-PDR when the nodes have static positions, irrespectively of the 802.11 standard used. Concerning the e-Throughput, AODV is in most cases the best choice. Lastly, HWMP has generally the worst performance in terms of e-PDR or e-Throughput except for some particular scenarios where it has an average performance.

\subsubsection{Mobile Position}

This subsection examines, which routing protocols manage the best energy when the nodes are mobile.

802.11a

Figure 14 and Figure 15 depict respectively the e-PDR and the e-Throughput for 802.11a in mobile position. According to Figure 14, OLSR is the best energy-efficient routing protocol in terms of e-PDR in the network of 16 nodes. Figure 15 reveals however that, AODV provides the best e-Throughput for the different transmission rates, irrespective of the size of the network. In the network of 49 nodes, AODV outperforms all the other protocol in terms of e-PDR and e-Throughput. From Figure 14, in the network of 100 nodes and for the transmission rates above $100 \mathrm{kbps}$, OLSR offers the best e-PDR. In some particular 


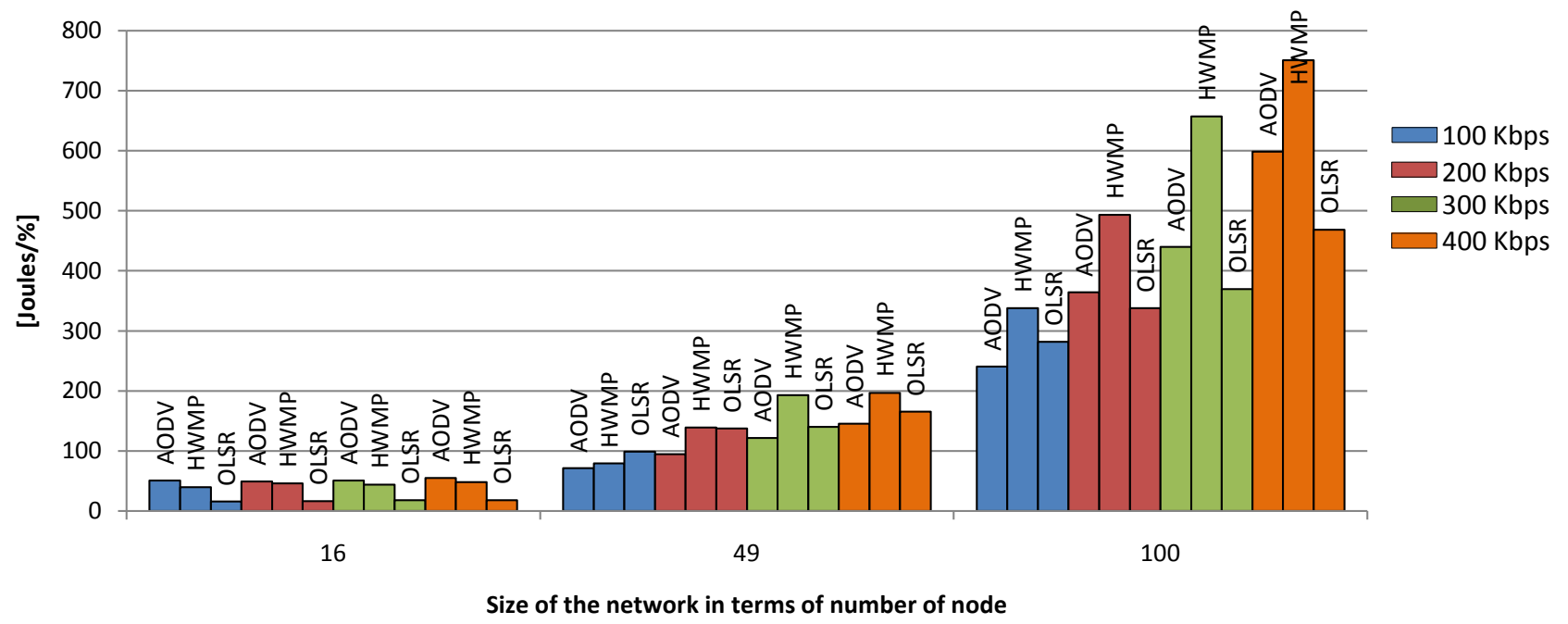

Figure 14. e-PDR for 802.11a in mobile position.

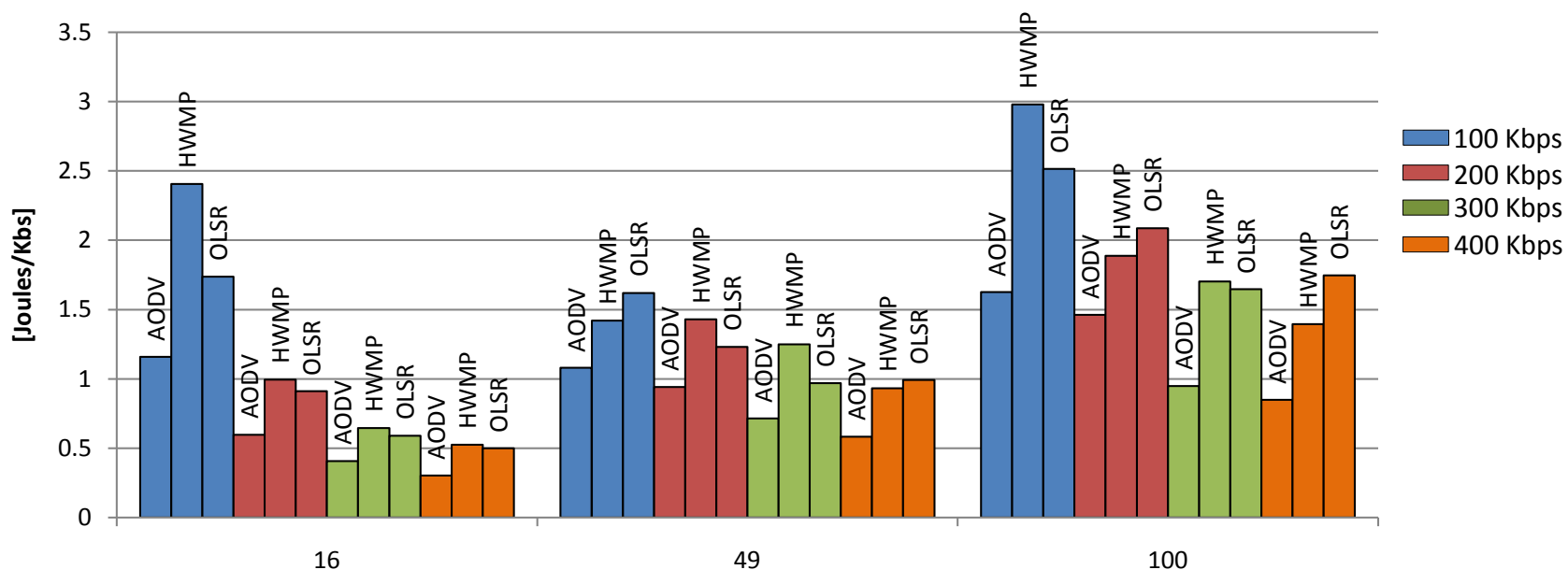

Size of the network in terms of number of node

Figure 15. e-Throughput for 802.11a in mobile position.

scenarios though HWMP does not provide the best performance, it can be considered as a good compromise.

\section{$802.11 b$}

Figure 16 and Figure 17 present the results obtained in different scenarios with all nodes using the $802.11 \mathrm{~b}$ standard. Figure 16 shows: OLSR is inarguably the best routing protocol in terms of e-PDR, followed by AODV in all scenarios. It is important to notice that HWMP offers a very bad e-PDR in scenarios with 100 nodes. That means, HWMP consumes a lot of energy but delivers very few packets. According to Figure 16, it is obvious that AODV has the best e-Throughput. OLSR performs very badly in relation to the e-Throughput at 100kbps; however, it manages its energy better at high transmission rates. So globally, OLSR offers the best e-PDR and AODV the best e-Throughput.

$802.11 \mathrm{~g}$

Figure 18 shows: OLSR has the best e-PDR in all scenarios irrespectively 


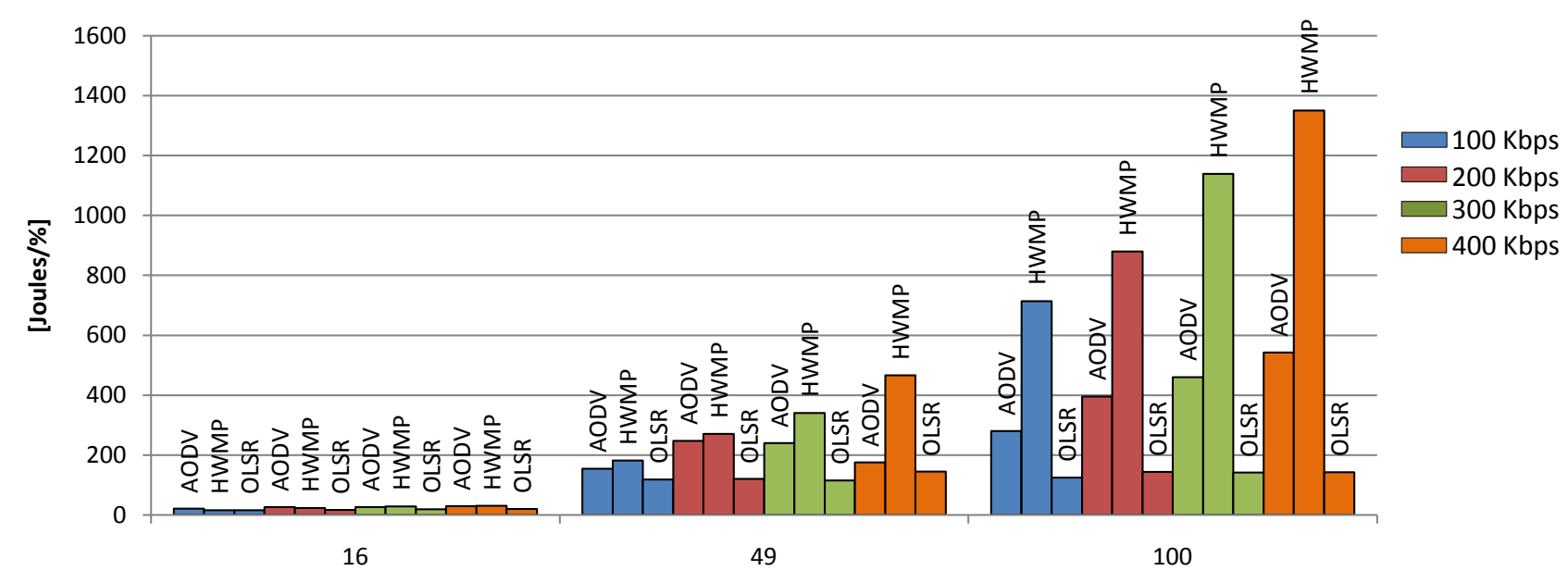

Size of the network in terms of number of node

Figure 16. e-PDR for $802.11 \mathrm{~b}$ in mobile position.

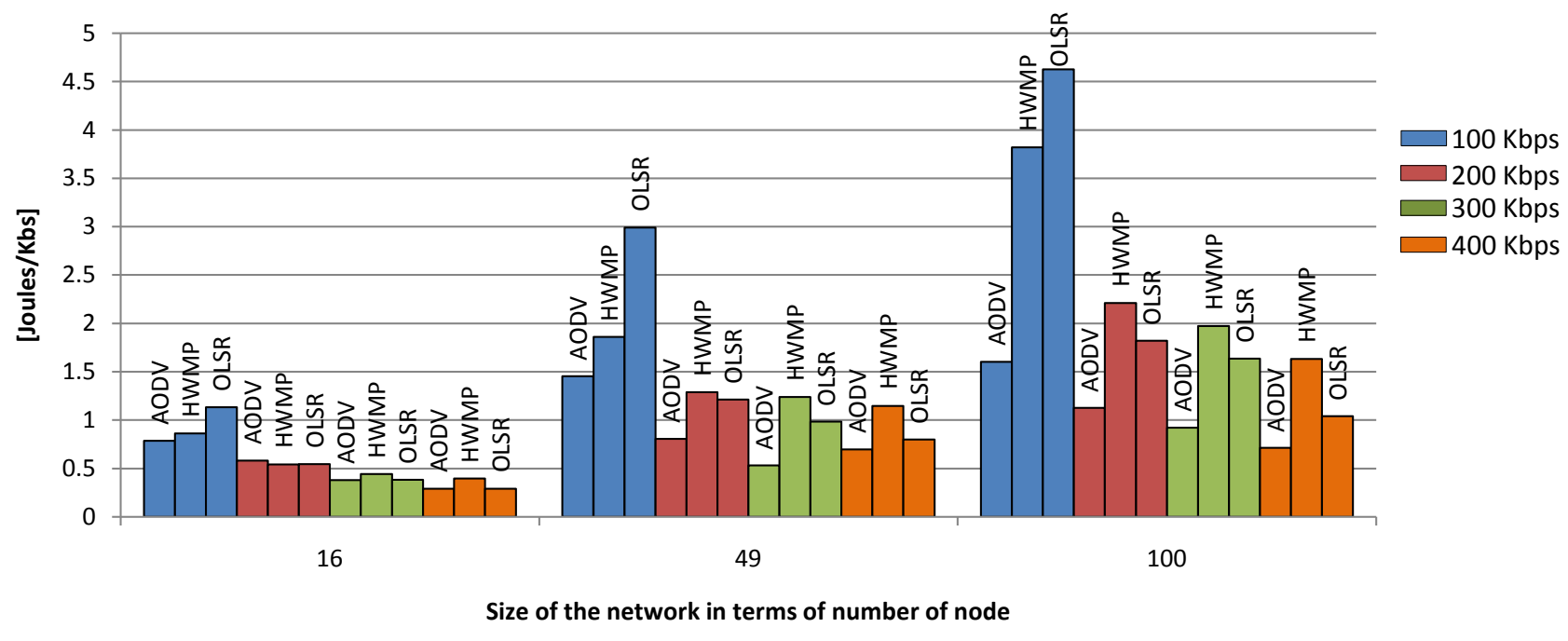

Figure 17. e-Throughput for $802.11 \mathrm{~b}$ in mobile position.

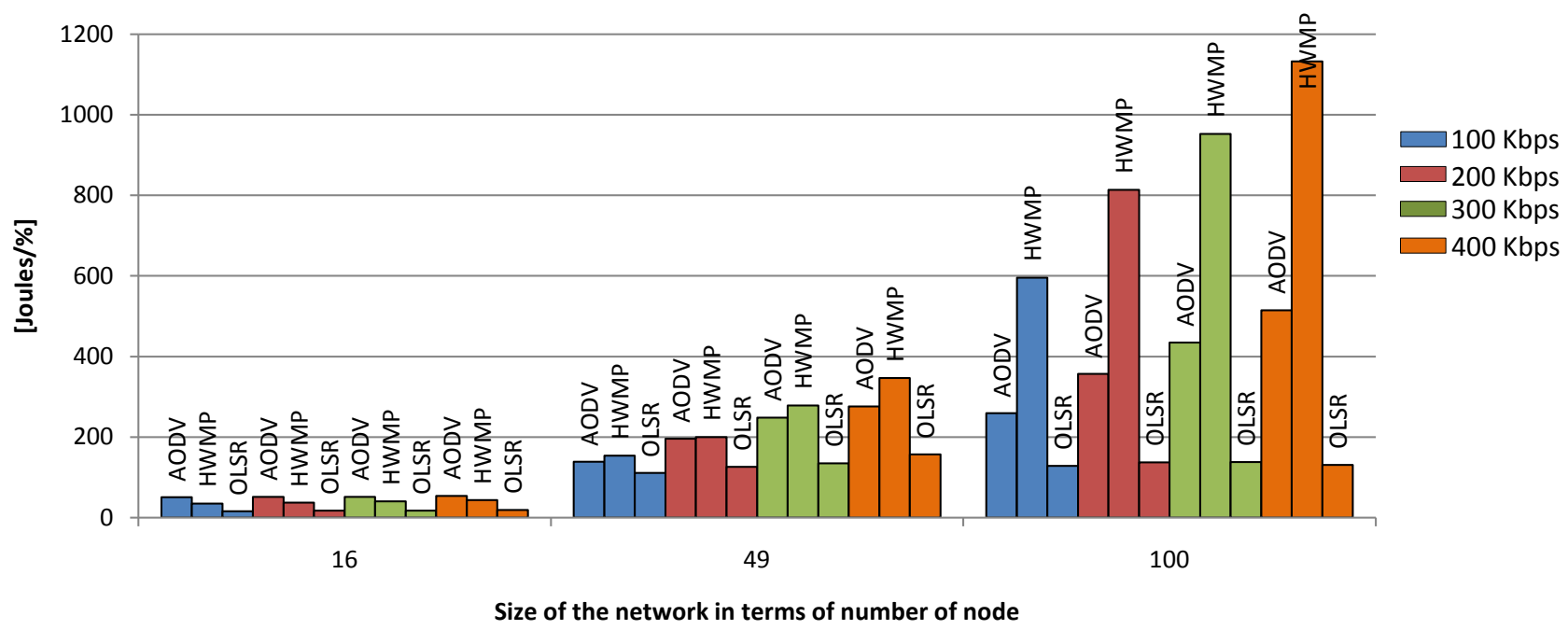

Figure 18. e-PDR for $802.11 \mathrm{~g}$ in mobile position. 
of the number of nodes and the traffic rate. Figure 19: AODV has the best e-Throughput in all scenarios irrespectively of the number of nodes and the traffic rate. However, HWMP though having the worst e-PDR for the network of 49 and 100 nodes gives an average performance in a good number of scenarios. OLSR is therefore doubtlessly the best option in similar scenarios to obtain the best e-PDR. AODV is inarguably the best choice to obtain the best e-Throughput. If an average solution is required in small network sizes, HWMP could be acceptable under some particular circumstances.

\subsection{Framework for Routing Protocol Selection}

At the light of the foregoing simulations and results, Table 6 provides a framework for choosing the best routing protocols respectively in constant and mobile position scenarios. It is constructed in two steps. The first step creates intermediate tables as follows: for each 802.11 standard, network size, and data rate, the protocol providing the best value of the considered metric is kept. The second step consists into selecting the protocols(s) with the larger occurrence(s) for each scenario (constant or mobile) from intermediate tables.

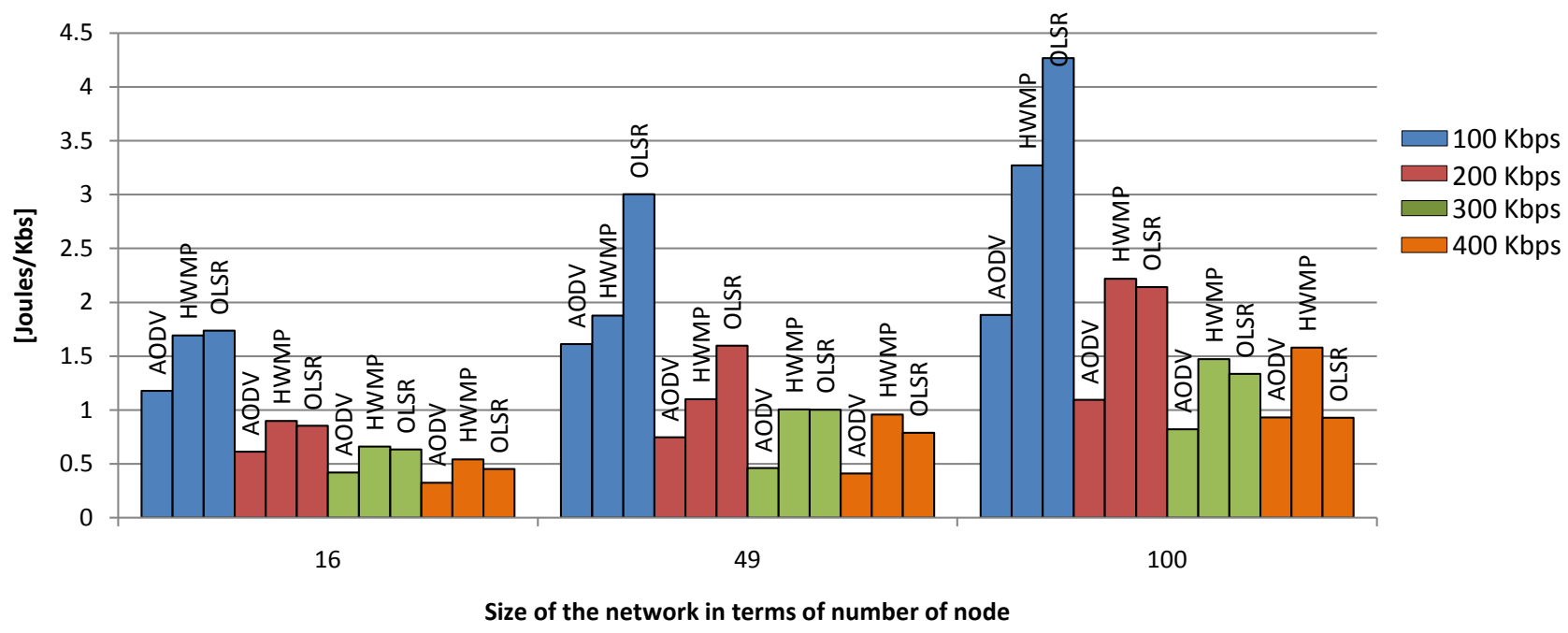

Figure 19. e-Throughput for $802.11 \mathrm{~g}$ in mobile position.

Table 6. Matrix for routing protocol selection.

\begin{tabular}{cccccc}
\hline Standard & Position & Energy & Throughput & e-PDR & e-Throughput \\
\hline 802.11a & Constant & HWMP & OLSR & OLSR & AODV/OLSR \\
& Mobile & AODV/HWMP & AODV & OLSR/AODV & AODV \\
& Constant & AODV & AODV & OLSR & AODV \\
$802.11 \mathrm{~b}$ & Mobile & AODV/OLSR & AODV/HWMP & OLSR & AODV/OLSR \\
& Constant & AODV & OLSR/AODV & OLSR & OLSR \\
\hline $802.11 \mathrm{~g}$ & Mobile & OLSR/AODV & AODV & AODV
\end{tabular}




\section{Conclusions}

We evaluated the performance of three routing protocols namely AODV, OLSR and HWMP with regard to energy consumption under NS3 in this work. We used random network topologies over different surface areas. We evaluated the impact of mobility over the energy consumption. In addition, we examined the impact of different WIFI standards over the energy consumption. Based on our observations, the energy consumed by each routing protocol varied according to the configuration used in our different scenarios. In fact, it emerged from this work that basically AODV could offer the minimum energy consumption followed by OLSR. HWMP could be also an adequate choice but in a particular configuration using the 802.11a standard. To refine this work, we introduced two performance metrics, the e-PDR and the e-throughput. At the end of our observations, OLSR is the protocol, which manages its energy consumption, the best way to deliver the highest fraction of packets. The AODV protocol provided the best e-throughput in overall configurations. Despite its worst performances in most cases, HWMP has been seen for some particular situations as the middle solution especially when using the 802.11a standard. Our results indicate that further refinement of the 802.11s based HWMP standard is required to reach the energy-efficiency of layer three's routing protocols. The framework for selecting an energy-efficient routing protocol can be useful during the design of wireless networks.

We considered the reactive mode of HWMP in this work. It would be interesting to consider also the proactive mode of this protocol. Furthermore, an analysis of the velocity of mobile nodes could provide insights into the energy consumption of those routing protocols in Vehicular Ad-hoc Networks and Flying Ad-hoc Networks.

\section{References}

[1] Akyildiz, I.F., Wang, X. and Wang, W. (2005) Wireless Mesh Networks: A Survey. Computer Networks, 47, 445-487. https://doi.org/10.1016/j.comnet.2004.12.001

[2] Badawy, G.H., Sayegh, A.A. and Todd, T.D. (2010) Energy Provisioning in Solar-Powered Wireless Mesh Networks. IEEE Transactions on Vehicular Technology, 59, 3859-3871. https://doi.org/10.1109/TVT.2010.2064797

[3] Bahr, M. (2006) Proposed Routing for IEEE 802.11s WLAN Mesh Networks. Proceedings of the 2nd Annual International Workshop on Wireless Internet, WICON 06, 2-5 August 2006, Boston, Massachusetts, 5-es. https://doi.org/10.1145/1234161.1234166

[4] Barati, M., Atefi, K., Khosravi, F. and Daftari, Y.A. (2012) Performance Evaluation of Energy Consumption for AODV and DSR Routing Protocols in MANET. 2012 International Conference on Computer \& Information Science (ICCIS), 12-14 June 2012, Kuala Lumpeu, 636-642. https://doi.org/10.1109/ICCISci.2012.6297107

[5] Bernardi, G., Buneman, P. and Marina, M.K. (2008) Tegola Tiered Mesh Network Testbed in Rural Scotland. Proceedings of the 2008 ACM Workshop on Wireless Networks and Systems for Developing Regions, 19-19 September 2008, San Francisco, California, 9-16. https://doi.org/10.1145/1410064.1410067 
[6] Broch, J., Maltz, D.A. and Johnson, D.B. (1998) A Performance Comparison of Multi-Hop Wireless Ad Hoc Network Routing Protocols. Proceedings of the 4th Annual ACM/IEEE International Conference on Mobile Computing and Networking, 25-30 October 1998, Dallas, Texas, 1-13. https://doi.org/10.1145/288235.288256

[7] Cano, J.-C. and Manzoni, P. (2000) A Performance Comparison of Energy Consumption for Mobile Ad Hoc Network Routing Protocols. Proceedings of 8th International Symposium on Modeling, Analysis and Simulation of Computer and Telecommunication Systems, 29 August-1 September 2000, San Francisco, CA, Cat. No. PR00728, 57-64. https://doi.org/10.1109/MASCOT.2000.876429

[8] Cao, L., Dahlberg, T. and Wang, Y. (2007) Performance Evaluation of Energy Efficient Ad Hoc Routing Protocols. 2007 IEEE International Performance, Computing, and Communications Conference, 11-13 April 2007, New Orleans, LA, 306-313. https://doi.org/10.1109/PCCC.2007.358908

[9] Chen, B. and Chang, C.H. (2003) Mobility Impact on Energy Conservation of Ad Hoc Routing Protocols. SSGRR 2003.

[10] Clausen, T. and Jacquet, P. (2003) Optimized Link State Routing Protocol (OLSR). Ietf Rfc3626, 75. https://doi.org/10.17487/rfc3626

[11] Corson, S. and Macker, J. (1999) Mobile Ad Hoc Networking (MANET): Routing Protocol Performance Issues and Evaluation Considerations. Computing Systems, 54, 1-12. http://www.ietf.org/rfc/rfc2501.txt https://doi.org/10.17487/rfc2501

[12] Fendji Kedieng Ebongue, J.L. and Nlong, J.M. (2015) Rural Wireless Mesh Network: A Design Methodology. International Journal of Communications, Network and System Sciences, 8, 1-9. https://doi.org/10.4236/ijcns.2015.81001

[13] Fotino, M., Gozzi, A., Rango, F., De Marano, S., Cano, J. and Calafate, C. (2007) Evaluating Energy-Aware Behavior of Proactive and Reactive Routing Protocols for Mobile Ad Hoc Networks. International Symposium on Performance Evaluation of Computer and Telecommunication Systems (SPECTS 2007), 16-18 July 2007, San Diego, CA, USA.

[14] Garcia, J.-E., Kallel, A., Kyamakya, K., Jobmann, K., Cano, J.-C. and Manzoni, P. (2003) A Novel DSR-Based Energy-Efficient Routing Algorithm for Mobile Ad-Hoc Networks. 2003 IEEE 58th Vehicular Technology Conference VTC 2003-Fall, 6-9 October 2003, Orlando, FL, Cat. No. 03CH37484, 2849-2854.

https://doi.org/10.1109/VETECF.2003.1286127

[15] Gupta, N. and Das, S.R. (2002) Energy-Aware On-Demand Routing for Mobile Ad Hoc Networks. International Workshop on Distributed Computing (IWDC 2002), 28-31 December 2002, Kolkata, India, 164-173. https://doi.org/10.1007/3-540-36385-8_17

[16] Halperin, D. and Greenstein, B. (2010) Demystifying 802.11 n Power Consumption. Workshop on Power Aware Computing and Systems (HotPower' 10), 4-6 October 2010, Vancouver, BC, Canada, 2-6. http://static.usenix.org/event/hotpower/tech/full_papers/Halperin.pdf

[17] Hawa, M., Taifour, S., Qasem, M. and Tuffaha, W. (2012) A Dynamic Cross-Layer Routing Protocol for Mobile Ad Hoc Networks. AEU-International Journal of Electronics and Communications, 66, 996-1005. https://doi.org/10.1016/j.aeue.2012.05.002

[18] Houaidia, C., Idoudi, H., Van Den Bossche, A., Val, T. and Saidane, L.A. (2013) Impact of IEEE 802.11 PHY/MAC Strategies on Routing Performance in Wireless Mesh Networks. Proceedings of 27 th International Conference on Advanced Information Networking and Applications Workshops (WAINA 2013), 25-28 March 
2013, Barcelona, 803-808. https://doi.org/10.1109/WAINA.2013.2

[19] Kim, J.-M. and Jang, J.-W. (2006) AODV Based Energy Efficient Routing Protocol for Maximum Lifetime in MANET. Int'l Conference on Telecommunications on Internet and Web Applications and Services/ Advanced International Conference on Telecommunications (AICT-ICIW 06), 19-25 February 2006, Guadelope, 77-77. https://doi.org/doi:10.1109/AICT-ICIW.2006.49

[20] Johnson, D.B. and Maltz, D.A. (1996) Dynamic Source Routing in Ad Hoc Wireless Networks. Mobile Computing, 353, 153-181. https://doi.org/10.1007/b102605

[21] Kafhali, S.E.L. and Haqiq, A. (2013) Effect of Mobility and Traffic Models on the Energy Consumption in MANET Routing Protocols. International Journal of Soft Computing and Engineering (IJSCE), 3, 242-249.

[22] Kuchaki Rafsanjani, M. and Fatemidokht, H. (2015) FBeeAdHoc: A Secure Routing Protocol for BeeAdHoc Based on Fuzzy Logic in MANETs. AEU-International Journal of Electronics and Communications, 69, 1613-1621. https://doi.org/10.1016/j.aeue.2015.07.013

[23] Kunz, T. (2008) Energy-Efficient Variations of OLSR. IWCMC 2008-International Wireless Communications and Mobile Computing Conference, 6-8 August 2008, Crete Island, 517-522. https://doi.org/10.1109/IWCMC.2008.90

[24] Maan, F. and Mazhar, N. (2011) MANET Routing Protocols vs Mobility Models: A Performance Evaluation. 2011 3rd International Conference on Ubiquitous and Future Networks (ICUFN), 15-17 June 2011, Dalian, 179-184. https://doi.org/10.1109/ICUFN.2011.5949158

[25] Macker, J.P. and Corson, M.S. (1998) Mobile ad Hoc Networking and the IETF. ACM SIGMOBILE Mobile Computing and Communications, 2, 9-13. https://doi.org/10.1145/1321400.1321409

[26] Mahfoudh, S. and Minet, P. (2008) An Energy Efficient Routing Based on OLSR in Wireless Ad Hoc and Sensor Networks. 22nd International Conference on Advanced Information Networking and Applications-Workshops (AINAW 2008), 25-28 March 2008, Okinawa, 1253-1259. https://doi.org/10.1109/WAINA.2008.60

[27] Matsuo, K., Oda, T., Elmazi, D., Sakamoto, S. and Barolli, L. (2015) Performance Evaluation of AODV, OLSR and HWMP Protocols in Ad-Hoc Networks and MANET Scenarios. Proceedings of 2015 9th International Conference on Innovative Mobile and Internet Services in Ubiquitous Computing (IMIS 2015), 8-10 July 2015, Blumenau, 15-21. https://doi.org/10.1109/IMIS.2015.7

[28] Min, B.C., Kim, Y., Lee, S., Jung, J.W. and Matson, E.T. (2015) Finding the Optimal Location and Allocation of Relay Robots for Building a Rapid End-to-End Wireless Communication. Ad Hoc Networks, 39, 23-44. https://doi.org/doi:10.1016/j.adhoc.2015.12.001

[29] Park, V. and Corson, S. (2001) Temporally-Ordered Routing Algorithm (TORA) Version 1 Functional Specification. IETF MANET Working Group INTERNET-DRAFT, January 2002, 1-23.

[30] Perkings, C., Belding-Royer, E. and Das, S. (2003) Ad Hoc On-Demand Distance Vector (AODV) Routing. IetfRfc 3561, 1-37.

[31] Perkins, C.E. and Bhagwat, P. (1994) Highly Dynamic Destination-Sequenced Distance-Vector Routing (DSDV) for Mobile Computers. ACM SIGCOMM Computer Communication Review, 24, 234-244. https://doi.org/10.1145/190809.190336

[32] Setty, S. and Prasad, B. (2011) Comparative Study of Energy Aware QoS for Proactive and Reactive Routing Protocols for Mobile Ad-Hoc Networks. International 
Journal of Computer Applications, 31, 1-6.

[33] Vasiliev, D.S., Meitis, D.S. and Abilov, A. (2014) Simulation-Based Comparison of AODV, OLSR and HWMP Protocols for Flying Ad Hoc Networks. International Conference on Next Generation Wired/ Wireless Networking, 8638, 245-252. https://doi.org/10.1007/978-3-319-10353-2_21

[34] Weingärtner, E., Vom Lehn, H. And Wehrle, K. (2009) A Performance Comparison of Recent Network Simulators. IEEE International Conference on Communications, 14-18 June 2009, Dresden. https://doi.org/10.1109/ICC.2009.5198657

[35] Zakaria, A., Mohamad, H., Ramli, N. and Ismail, M. (2013) Performance Evaluation of Routing Protocols in Wireless Mesh Network. ICACT 2013, 27-30 January 2013, 1111-1115. http://www.icact.org/upload/2013/0446/20130446_finalpaper.pdf

[36] HP Invent. QuickSpecs HP Compaq nx6310 Notebook PC. http://www.tcmi.com/Products/sysimages/nx6310.pdf

[37] https://www.nsnam.org/doxygen/

[38] Zhang, D.G., Song, X.D., Wang, X. and Ma, Y.Y. (2014) Extended AODV Routing Method Based on Distributed Minimum Transmission (DMT) for WSN. AEU-International Journal of Electronics and Communications, 69, 371-381. https://doi.org/10.1016/j.aeue.2014.10.009 


\section{Appendix A: Results of Simulation}

Table A1. 802.11a mobile scenario.

\begin{tabular}{|c|c|c|c|c|c|c|c|c|c|c|c|c|}
\hline \multicolumn{13}{|c|}{ Energy $(J)$} \\
\hline \multirow{2}{*}{ Nodes } & \multicolumn{3}{|c|}{100} & \multicolumn{3}{|c|}{200} & \multicolumn{3}{|c|}{300} & \multicolumn{3}{|c|}{400} \\
\hline & AODV & HWMP & OLSR & AODV & HWMP & OLSR & AODV & HWMP & OLSR & AODV & HWMP & OLSR \\
\hline 16 & 608.663 & 631.613 & 630.348 & 619.134 & 650.686 & 658.287 & 628.877 & 672.863 & 693.478 & 636.469 & 689.267 & 719.887 \\
\hline 49 & 2826.19 & 3939.4 & 3959.08 & 3580.58 & 5664.8 & 5161.64 & 4145.44 & 6252.01 & 5809.56 & 4591.57 & 6135.82 & 6264.09 \\
\hline 100 & 5245.94 & 5117.11 & 5092.33 & 6068.71 & 5254.64 & 6062.5 & 6327.04 & 5621.52 & 6620.24 & 6716.16 & 5680.29 & 7152.77 \\
\hline \multicolumn{13}{|c|}{ Throughput (Kbps) } \\
\hline \multirow{2}{*}{ Nodes } & & 100 & & & 200 & & & 300 & & & 400 & \\
\hline & AODV & HWMP & OLSR & AODV & HWMP & OLSR & AODV & HWMP & OLSR & AODV & HWMP & OLSR \\
\hline 16 & 525.123 & 262.585 & 362.983 & 1036.29 & 653.775 & 721.977 & 1542.06 & 1043.19 & 1177.04 & 2102.21 & 1310.74 & 1438.6 \\
\hline 49 & 2617.31 & 2775.47 & 2443.23 & 3803.62 & 3963.94 & 4197.3 & 5803.08 & 5002.44 & 6000.61 & 7886.96 & 6581.76 & 6314.78 \\
\hline 100 & 3226.79 & 1717.51 & 2024.32 & 4151.64 & 2784.98 & 2905.67 & 6666.48 & 3300.84 & 4021.39 & 7907.82 & 4069.03 & 4092.85 \\
\hline \multicolumn{13}{|c|}{ PDR (\%) } \\
\hline \multirow{2}{*}{ Nodes } & & 100 & & & 200 & & & 300 & & & 400 & \\
\hline & AODV & HWMP & OLSR & AODV & HWMP & OLSR & AODV & HWMP & OLSR & AODV & HWMP & OLSR \\
\hline 16 & 12.0112 & 15.8416 & 40.2158 & 12.6207 & 14.1129 & 39.9786 & 12.3537 & 15.3312 & 38.7755 & 11.6073 & 14.2485 & 40.0573 \\
\hline 49 & 39.6079 & 49.8217 & 39.9944 & 37.7486 & 40.6748 & 37.4928 & 34.0759 & 32.3989 & 41.384 & 31.5644 & 31.226 & 37.8822 \\
\hline 100 & 21.8136 & 15.1535 & 18.0846 & 16.6592 & 10.6528 & 17.9487 & 14.3815 & 8.55312 & 17.9046 & 11.221 & 7.566 & 15.2665 \\
\hline
\end{tabular}

Table A2. 802.11a constant scenario.

\begin{tabular}{|c|c|c|c|c|c|c|c|c|c|c|c|c|}
\hline \multicolumn{13}{|c|}{ Energy (J) } \\
\hline \multirow{2}{*}{ Nodes } & \multicolumn{3}{|c|}{100} & \multicolumn{3}{|c|}{200} & \multicolumn{3}{|c|}{300} & \multicolumn{3}{|c|}{400} \\
\hline & AODV & HWMP & OLSR & AODV & HWMP & OLSR & AODV & HWMP & OLSR & AODV & HWMP & OLSR \\
\hline 16 & 699.627 & 676 & 704.698 & 826.954 & 763.014 & 809.662 & 873.804 & 896.044 & 929.379 & 917.668 & 936.333 & 1033.86 \\
\hline 49 & 3617.58 & 3502.65 & 4107.61 & 4305.08 & 4859.51 & 5858.08 & 4764.57 & 4556.35 & 6318.45 & 5052.9 & 5993.43 & 6939.26 \\
\hline 100 & 5098.16 & 4165.51 & 5877.42 & 5877.68 & 4953.48 & 7024.78 & 6215.43 & 4499.42 & 7515.93 & 6374.21 & 4544.5 & 7967.06 \\
\hline \multicolumn{13}{|c|}{ Throughput (Kbps) } \\
\hline \multirow{2}{*}{ Nodes } & & 100 & & & 200 & & & 300 & & & 400 & \\
\hline & AODV & HWMP & OLSR & AODV & HWMP & OLSR & AODV & HWMP & OLSR & AODV & HWMP & OLSR \\
\hline 16 & 989.467 & 795.203 & 1086.55 & 1934.89 & 1600.76 & 1963.18 & 2777.51 & 2367.51 & 3119.84 & 3638.51 & 3091.83 & 3916.2 \\
\hline 49 & 3649.88 & 2638.1 & 4139.13 & 6042.48 & 5294.31 & 6453.15 & 7659.03 & 6425.06 & 7223.84 & 8430.3 & 8038.08 & 8608.48 \\
\hline 100 & 3163.63 & 1588.39 & 4301.76 & 4756.19 & 3328.08 & 5144.92 & 6587.64 & 3823.54 & 7541.38 & 7802.08 & 4777.62 & 6710.79 \\
\hline
\end{tabular}




\section{Continued}

PDR (\%)

\begin{tabular}{ccccccccccccccc} 
Nodes & \multicolumn{3}{c}{100} & \multicolumn{1}{c}{200} & \multicolumn{4}{c}{300} & & & 400 & \\
& AODV & HWMP & OLSR & AODV & HWMP & OLSR & AODV & HWMP & OLSR & AODV & HWMP & OLSR \\
16 & 60.8842 & 47.2439 & 99.9696 & 59.4759 & 46.609 & 99.9543 & 57.0537 & 46.7936 & 98.4127 & 51.8694 & 44.7917 & 94.1702 \\
49 & 72.013 & 62.2528 & 86.5374 & 56.4899 & 57.6739 & 65.5396 & 43.8762 & 41.5634 & 57.7068 & 40.0644 & 36.5361 & 51.5139 \\
100 & 26.6631 & 11.4561 & 74.2007 & 19.5725 & 15.8514 & 62.206 & 16.6944 & 9.98297 & 47.7853 & 14.0211 & 8.83988 & 49.2154 \\
\hline
\end{tabular}

Table A3. 802.11b mobile scenario.

\begin{tabular}{|c|c|c|c|c|c|c|c|c|c|c|c|c|}
\hline \multicolumn{13}{|c|}{ Energy $(J)$} \\
\hline \multirow{2}{*}{ Nodes } & \multicolumn{3}{|c|}{100} & \multicolumn{3}{|c|}{200} & \multicolumn{3}{|c|}{300} & \multicolumn{3}{|c|}{400} \\
\hline & AODV & HWMP & OLSR & AODV & HWMP & OLSR & AODV & HWMP & OLSR & AODV & HWMP & OLSR \\
\hline 16 & 749.02 & 990.7 & 785.262 & 860.46 & 1192.37 & 918.527 & 897.852 & 1264 & 968.245 & 1001.97 & 1545.97 & 1023.26 \\
\hline 49 & 2182.88 & 3208.21 & 2086.41 & 2350.08 & 3593.94 & 2250.05 & 2423.21 & 3790.51 & 2289.17 & 5550.69 & 3975.82 & 2303 \\
\hline 100 & 4860.46 & 6656.76 & 4166.86 & 5175.46 & 6890.54 & 4368.53 & 5465.98 & 7423.09 & 4438.1 & 5662.32 & 7609.67 & 4491.98 \\
\hline \multicolumn{13}{|c|}{ Throughput (Kbps) } \\
\hline \multirow{2}{*}{ Nodes } & & 100 & & \multicolumn{3}{|c|}{200} & \multicolumn{3}{|c|}{300} & \multicolumn{3}{|c|}{400} \\
\hline & AODV & HWMP & OLSR & AODV & HWMP & OLSR & AODV & HWMP & OLSR & AODV & HWMP & OLSR \\
\hline 16 & 952.064 & 1150.09 & 692.092 & 1478.76 & 2199.29 & 1679.67 & 2366.66 & 2851.06 & 2520.78 & 3427.41 & 3902.18 & 3500.64 \\
\hline 49 & 1501.71 & 1725.65 & 697.617 & 2918.15 & 2789.68 & 1855.26 & 4556.73 & 3055.18 & 2327.39 & 7954.55 & 3463.86 & 2874.89 \\
\hline 100 & 3029.02 & 1741.83 & 900.509 & 4597.94 & 3117.89 & 2400.56 & 5934.03 & 3765.16 & 2712.71 & 7926.59 & 4663.05 & 4318.09 \\
\hline \multicolumn{13}{|c|}{ PDR (\%) } \\
\hline \multirow{2}{*}{ Nodes } & & 100 & & & 200 & & & 300 & & & 400 & \\
\hline & AODV & HWMP & OLSR & AODV & HWMP & OLSR & AODV & HWMP & OLSR & AODV & HWMP & OLSR \\
\hline 16 & 35.2066 & 61.1546 & 47.9377 & 32.572 & 52.4235 & 55.7533 & 33.6847 & 44.3438 & 51.7532 & 34.1719 & 51.2416 & 52.1881 \\
\hline 49 & 14.0922 & 17.6702 & 17.6166 & 9.49347 & 13.2905 & 18.663 & 10.1115 & 11.1361 & 19.8928 & 31.6957 & 8.53435 & 15.8524 \\
\hline 100 & 17.3231 & 9.32025 & 33.464 & 13.0738 & 7.8335 & 30.4479 & 11.8732 & 6.52005 & 31.3366 & 10.4435 & 5.63523 & 31.4504 \\
\hline
\end{tabular}

Table A4. 802.11b constant scenario.

\begin{tabular}{|c|c|c|c|c|c|c|c|c|c|c|c|c|}
\hline \multicolumn{13}{|c|}{ Energy (J) } \\
\hline \multirow{2}{*}{ Nodes } & \multicolumn{3}{|c|}{100} & \multicolumn{3}{|c|}{200} & \multicolumn{3}{|c|}{300} & \multicolumn{3}{|c|}{400} \\
\hline & AODV & HWMP & OLSR & AODV & HWMP & OLSR & AODV & HWMP & OLSR & AODV & HWMP & OLSR \\
\hline 16 & 737.413 & 924.661 & 778.344 & 865.395 & 1161.54 & 932.746 & 1045.86 & 1361.49 & 1114.58 & 1123.82 & 1637.45 & 1230.93 \\
\hline 49 & 2507.21 & 2912.95 & 2693.58 & 2880.03 & 3473.37 & 3125.11 & 3092.53 & 3685.65 & 3200.88 & 3254.18 & 3686.21 & 3265.05 \\
\hline 100 & 4871.74 & 6074.75 & 5159.34 & 5206.12 & 6975.7 & 5783.52 & 5630.11 & 7138.6 & 5770.62 & 5604.49 & 6835.53 & 5883.78 \\
\hline
\end{tabular}


Throughput (Kbps)

100

Nodes

00

300

400

\begin{tabular}{|c|c|c|c|c|c|c|c|c|c|c|c|c|}
\hline & AODV & HWMP & OLSR & AODV & HWMP & OLSR & AODV & HWMP & OLSR & AODV & HWMP & OLSR \\
\hline 16 & 1092.55 & 1064.38 & 943.022 & 2169.32 & 2107.08 & 1888.24 & 3179.14 & 3074.99 & 2740.34 & 4066.5 & 4031.85 & 3511.3 \\
\hline 49 & 1578.39 & 1039.16 & 784.872 & 2037.17 & 1339.57 & 932.105 & 2562.96 & 1462.57 & 883.735 & 2549.91 & 1455.09 & 926.996 \\
\hline 100 & 1876.04 & 1524.91 & 1146.71 & 2558.18 & 2078.84 & 1778.26 & 3310.37 & 2230.81 & 2014.6 & 3858.46 & 2134.1 & 2926.91 \\
\hline \multicolumn{13}{|c|}{ PDR (\%) } \\
\hline \multirow{3}{*}{ Nodes } & & 100 & & & 200 & & & 300 & & & 400 & \\
\hline & & & & & & & & & & & & \\
\hline & AODV & HWMP & OLSR & AODV & HWMP & OLSR & AODV & HWMP & OLSR & AODV & HWMP & OLSR \\
\hline 16 & 60.7449 & 60.0745 & 95.2641 & 60.7312 & 59.3637 & 95.4656 & 57.5602 & 58.9184 & 92.9835 & 60.4678 & 57.6311 & 92.7077 \\
\hline 49 & 35.5132 & 22.5118 & 53.4188 & 25.2817 & 15.013 & 31.2075 & 19.4504 & 11.3597 & 27.2592 & 15.6673 & 8.38277 & 23.9244 \\
\hline 100 & 19.5628 & 14.1761 & 44.623 & 12.7038 & 10.0026 & 27.3875 & 10.5005 & 4.86473 & 23.7695 & 9.03143 & 3.81875 & 30.7177 \\
\hline
\end{tabular}

Table A5. 802.11g mobile scenario.

\begin{tabular}{|c|c|c|c|c|c|c|c|c|c|c|c|c|}
\hline \multicolumn{13}{|c|}{ Energy (J) } \\
\hline \multirow{2}{*}{ Nodes } & \multicolumn{3}{|c|}{100} & \multicolumn{3}{|c|}{200} & \multicolumn{3}{|c|}{300} & \multicolumn{3}{|c|}{400} \\
\hline & AODV & HWMP & OLSR & AODV & HWMP & OLSR & AODV & HWMP & OLSR & AODV & HWMP & OLSR \\
\hline 16 & 617.363 & 681.035 & 640.545 & 627.779 & 719.609 & 670.045 & 644.666 & 760.73 & 696.749 & 657.21 & 801.226 & 708.718 \\
\hline 49 & 2185.35 & 2953.46 & 2095.28 & 2297.77 & 3391.46 & 2228.79 & 2376 & 3499.03 & 2263.82 & 2435.61 & 3650.16 & 2385.98 \\
\hline 100 & 4800.55 & 6238.2 & 4155.23 & 4996.46 & 6888.23 & 4320 & 5284.12 & 6567.14 & 4468.9 & 5393.7 & 7238.29 & 4407.48 \\
\hline \multicolumn{13}{|c|}{ Throughput (Kbps) } \\
\hline Nodes & & 100 & & & 200 & & & 300 & & & 400 & \\
\hline 16 & 524.264 & 402.262 & 368.855 & 1025.39 & 801.457 & 786.242 & 1534.65 & 1151.89 & 1098.77 & 2023.76 & 1483.41 & 1568.15 \\
\hline 49 & 1355.16 & 1573.58 & 697.838 & 3073.95 & 3078.01 & 1396.47 & 5154.8 & 3475.64 & 2260.46 & 5925.91 & 3814.65 & 3031.75 \\
\hline 100 & 2547.57 & 1906.6 & 973.539 & 4567.24 & 3103.19 & 2017.95 & 6430.74 & 4462.43 & 3344.56 & 5793.42 & 4585.12 & 4750.98 \\
\hline \multicolumn{13}{|c|}{$\operatorname{PDR}(\%)$} \\
\hline \multirow{2}{*}{ Nodes } & & 100 & & & 200 & & & 300 & & & 400 & \\
\hline & AODV & HWMP & OLSR & AODV & HWMP & OLSR & AODV & HWMP & OLSR & AODV & HWMP & OLSR \\
\hline 16 & 12.0484 & 19.3855 & 40.5308 & 12.1747 & 19.3972 & 38.974 & 12.5293 & 18.9531 & 40.4134 & 12.2514 & 18.2385 & 37.4928 \\
\hline 100 & 18.4977 & 10.4744 & 32.3907 & 14.0147 & 8.46885 & 31.4245 & 12.1664 & 6.89385 & 32.3138 & 10.4738 & 6.39116 & 33.7362 \\
\hline
\end{tabular}


Table A6. 802.11g constant scenario.

\begin{tabular}{|c|c|c|c|c|c|c|c|c|c|c|c|c|}
\hline \multicolumn{13}{|c|}{ Energy $(J)$} \\
\hline \multirow{2}{*}{ Nodes } & \multicolumn{3}{|c|}{100} & \multicolumn{3}{|c|}{200} & \multicolumn{3}{|c|}{300} & \multicolumn{3}{|c|}{400} \\
\hline & AODV & HWMP & OLSR & AODV & HWMP & OLSR & AODV & HWMP & OLSR & AODV & HWMP & OLSR \\
\hline 16 & 729.846 & 795.318 & 741.462 & 858.422 & 928.307 & 872.848 & 999.752 & 1067.53 & 1007.83 & 1076.62 & 1112.23 & 1119.06 \\
\hline 49 & 2389.74 & 2804.25 & 2466.74 & 2748.6 & 3482.23 & 4968.64 & 2938.79 & 3997.84 & 3641.03 & 3017.53 & 4045.04 & 3809.72 \\
\hline 100 & 4696.8 & 5486.47 & 4775.64 & 5177.59 & 6271.23 & 5861.3 & 5301.21 & 6472.74 & 6013.25 & 5499.64 & 6780.94 & 6182.2 \\
\hline \multicolumn{13}{|c|}{ Throughput (Kbps) } \\
\hline \multirow{2}{*}{ Nodes } & & 100 & & \multicolumn{3}{|c|}{200} & \multicolumn{3}{|c|}{300} & \multicolumn{3}{|c|}{400} \\
\hline & AODV & HWMP & OLSR & AODV & HWMP & OLSR & AODV & HWMP & OLSR & AODV & HWMP & OLSR \\
\hline 16 & 1094.94 & 1096.51 & 1089.82 & 1736.69 & 2112.51 & 2152.76 & 2916.98 & 3009.68 & 3123.77 & 4016.2 & 3559.97 & 3601.9 \\
\hline 49 & 1605.56 & 1639.35 & 1672.35 & 2417.01 & 2873.01 & 4841.37 & 2895.52 & 2794.2 & 3245.6 & 3411.52 & 2633.23 & 2894.27 \\
\hline 100 & 1861.95 & 2015.9 & 2025.93 & 2757.14 & 2924.27 & 2956.16 & 3744.86 & 3545.88 & 3123.4 & 3645.33 & 3639.08 & 3455.16 \\
\hline \multicolumn{13}{|c|}{ PDR (\%) } \\
\hline \multirow{2}{*}{ Nodes } & & 100 & & & 200 & & & 300 & & & 400 & \\
\hline & AODV & HWMP & OLSR & AODV & HWMP & OLSR & AODV & HWMP & OLSR & AODV & HWMP & OLSR \\
\hline 16 & 59.9441 & 61.1918 & 100 & 59.7579 & 60.6568 & 99.8029 & 58.5401 & 56.5244 & 98.6065 & 53.3436 & 42.1596 & 95.3222 \\
\hline 49 & 35.0005 & 35.869 & 99.6515 & 27.2276 & 30.808 & 56.7464 & 20.37 & 23.2649 & 67.4927 & 17.8983 & 15.1739 & 51.5981 \\
\hline 100 & 19.468 & 22.4986 & 95.302 & 13.5966 & 14.7175 & 64.7575 & 11.0774 & 10.6163 & 51.9102 & 9.23374 & 8.05576 & 44.3105 \\
\hline
\end{tabular}

